\title{
Warm Paleocene/Eocene climate as simulated in ECHAM5/MPI-OM
}

\author{
M. Heinemann ${ }^{1,2}$, J. H. Jungclaus ${ }^{1}$, and J. Marotzke ${ }^{1}$ \\ ${ }^{1}$ Max Planck Institute for Meteorology (MPI-M), Bundesstraße 53, 20146 Hamburg, Germany \\ ${ }^{2}$ International Max Planck Research School on Earth System Modelling (IMPRS-ESM), Bundesstraße 53, \\ 20146 Hamburg, Germany
}

Received: 7 April 2009 - Published in Clim. Past Discuss.: 5 May 2009

Revised: 15 October 2009 - Accepted: 9 November 2009 - Published: 15 December 2009

\begin{abstract}
We investigate the late Paleocene/early Eocene (PE) climate using the coupled atmosphere-ocean-sea ice model ECHAM5/MPI-OM. The surface in our PE control simulation is on average $297 \mathrm{~K}$ warm and ice-free, despite a moderate atmospheric $\mathrm{CO}_{2}$ concentration of $560 \mathrm{ppm}$. Compared to a pre-industrial reference simulation (PR), low latitudes are 5 to $8 \mathrm{~K}$ warmer, while high latitudes are up to $40 \mathrm{~K}$ warmer. This high-latitude amplification is in line with proxy data, yet a comparison to sea surface temperature proxy data suggests that the Arctic surface temperatures are still too low in our PE simulation.

To identify the mechanisms that cause the PE-PR surface temperature differences, we fit two simple energy balance models to the ECHAM5/MPI-OM results. We find that about $2 / 3$ of the PE-PR global mean surface temperature difference are caused by a smaller clear sky emissivity due to higher atmospheric $\mathrm{CO}_{2}$ and water vapour concentrations in PE compared to PR; $1 / 3$ is due to a smaller planetary albedo. The reduction of the pole-to-equator temperature gradient in $\mathrm{PE}$ compared to $\mathrm{PR}$ is due to (1) the large high-latitude effect of the higher $\mathrm{CO}_{2}$ and water vapour concentrations in $\mathrm{PE}$ compared to PR, (2) the lower Antarctic orography, (3) the smaller surface albedo at high latitudes, and (4) longwave cloud radiative effects. Our results support the hypothesis that local radiative effects rather than increased meridional heat transports were responsible for the "equable" PE climate.
\end{abstract}

\section{Introduction}

Simulating warm periods in Earth history is a major challenge in climate research. The very warm climates during the

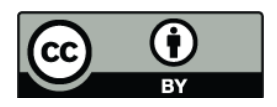

Correspondence to: M. Heinemann (malte.heinemann@zmaw.de) late Cretaceous to early Paleogene (about 100 to 35 million years ago) seem especially problematic, since model results are not consistent with paleo-reconstructions of low poleto-equator temperature gradients and reduced seasonalities on high-latitude continents. In this study, we aim at reducing this gap between modelling and proxy data for the late Paleocene/early Eocene (PE), about 55 million years ago. To this end, we set up a PE version of the coupled atmosphere-ocean-sea ice general circulation model (GCM) ECHAM5/MPI-OM. Using simple energy balance models as diagnostic tools, we quantify the mechanisms that lead to the warm climate in our PE GCM.

Evidence for the warm PE climate is provided by a wide range of proxies. Sea surface temperatures (SSTs) inferred from oxygen isotopes, $\mathrm{Mg} / \mathrm{Ca}$ ratios, and biomarkers suggest that the tropics were moderately warmer than at present, while high latitudes and especially Arctic temperatures were much warmer (e.g., Thomas et al., 2002; Tripati and Elderfield, 2004; Zachos et al., 2003, 2006; Sluijs et al., 2006). Estes and Hutchinson (1980) found warm-climate proxies such as salamanders, lizards, snakes, turtles, and an alligator on the Canadian Archipelago (see also Markwick, 1994, 1998). Greenwood and Scott (1995) inferred from the existence of high-latitude palm trees that a large part of the Earth surface, including continental interiors, had climates with winter temperatures much higher than today.

Climate models, employing large greenhouse gas concentrations, have been able to reproduce the high mean temperature of the PE. However, it has long been noticed that they fail to match the low pole-to-equator temperature gradient (Barron, 1987; Sloan and Barron, 1990; Huber and Sloan, 2001; Shellito et al., 2003, 2009). Note that, when Barron (1987) discussed the low pole-to-equator temperature gradient problem, it was believed that tropical SSTs during the PE were even lower than at present (e.g., Shackleton and Boersma, 1981). This led Barron (1987) to the conclusion that "the Eocene polar warmth could be explained by an

Published by Copernicus Publications on behalf of the European Geosciences Union. 
energy redistribution, a more efficient poleward heat transport, and external factors would be not required". Ever since, tropical temperature reconstructions have been adjusted towards warmer conditions (e.g., Sexton et al., 2006). If very high tropical temperatures are confirmed by further proxy analyses, the mismatch between models and proxy data may be reduced further (Huber, 2008).

Taking the warm poles, relatively cold tropics, and reduced seasonality inferred from proxy-data at face value, it has been suggested that the climate models lack one or more mechanisms that lead to such a so-called "equable" climate. Increased ocean heat transport has often been invoked to explain the problematic warm poles (e.g., Covey and Barron, 1988). Sloan et al. (1995) estimated that a $30 \%$ increase in poleward heat transport would be required to maintain Eocene high-latitude temperatures. Huber and Sloan (2001) revisited the hypothesis of increased oceanic heat transport, and simulated the Eocene with a fully coupled atmosphereocean-sea ice GCM, the Climate System Model (CSM) version 1.4 developed at the National Center for Atmospheric Research (NCAR). Their Eocene model solution showed a near-modern meridional temperature gradient, and a nearmodern oceanic heat transport. They concluded that the theory of increased ocean heat transport for maintaining low temperature gradients was incorrect or incomplete. Shellito et al. (2009), however, suggested that an open Bering Strait may have contributed to the warm Arctic surface during the early Eocene. Other hypotheses draw on local radiative changes rather than heat transport. Sloan and Pollard (1998) suggested that, given high atmospheric methane concentrations, polar stratospheric clouds might contribute to a high-latitude warming. Kump and Pollard (2008) found that increased cloud droplet radii and precipitation efficiency could cause an additional warming and high-latitude amplification. They argued that this change of the cloud properties could have been a response to a reduced global primary production by temperature stress, causing a reduction in cloud condensation nuclei concentration. Abbot and Tziperman (2008) suggested another mechanism related to clouds. They argued that deep convection during winter in ice-free highlatitude oceans might lead to high-latitude warming.

Still, to our knowledge, there is no PE model solution consistent with the geologic record. Modelling the PE remains a major challenge in climate research. We aim at testing whether the model-proxy data mismatch persists in a PE setup of the state-of-the-art coupled model ECHAM5/MPI$\mathrm{OM}$.

The boundary between the Paleocene and the Eocene is marked by an extraordinary, short-lived global warming event known as the Paleocene/Eocene Thermal Maximum (PETM), also named Late Paleocene Thermal Maximum (LPTM) or Eocene Thermal Maximum 1 (ETM1). This event is associated with a massive increase of atmospheric greenhouse gas concentrations (e.g., Dickens et al., 1995), and is frequently assumed to be an analogue for future green- house warming scenarios (e.g., Alley et al., 2002). Note that we aim at modelling the already warm background climate during the PE, not the PETM itself.

To better understand the processes that lead to the warm PE climate in our model, we compare the PE simulation to a pre-industrial reference simulation (PR). We briefly analyse the atmospheric and oceanic meridional heat transports in the PE model solution compared to PR. However, this study focuses on understanding the radiative effects responsible for the warm PE climate. Using two simple energy balance models, we assign the simulated warming of the PE climate compared to the PR climate to greenhouse gas forcing, albedo changes, cloud feedback processes, orographic effects, and orbital changes.

The paper is organised as follows. In Sect. 2, we describe the atmosphere-ocean-sea ice GCM ECHAM5/MPI-OM, focussing on the settings specific to the PE. In Sect. 3, we describe the simulated PE climate, briefly compare it to the geologic record, and highlight differences compared to PR. In Sect. 4, we introduce the simple EBMs as diagnostic tools, and analyse the different mechanisms that lead to the warm PE climate in our simulation. In Sect. 5, we present a discussion and conclusions.

\section{Model setup}

Our model ECHAM5/MPI-OM is based on the tropospheric model ECHAM5 resolving the atmosphere up to $10 \mathrm{hPa}$, the ocean-sea ice model MPI-OM, and the OASIS coupler. In the following section, we describe the basic model properties, boundary conditions, and parameter choices we use in the PE model setup.

\subsection{Atmosphere general circulation model}

The atmosphere general circulation model ECHAM5 (here: version 5.3, Roeckner et al., 2003) has been developed from the operational forecast model of the European Centre for Medium-Range Weather Forecasts (ECMWF) and a parameterisation package developed in Hamburg. ECHAM5 has a spectral dynamical core that solves the equations for vorticity, divergence, temperature and the logarithm of surface pressure in terms of spherical harmonics with a triangular truncation. Transport of water vapour, cloud liquid water, and cloud ice is computed on a Gaussian grid, using a fluxform semi-Lagrangian scheme (Lin and Rood, 1996). We use the spectral truncation T31, which corresponds to a Gaussian grid with a gridpoint spacing of approximately $3.75^{\circ}$.

The shortwave radiation scheme (Fouquart and Bonnel, 1980) has four spectral bands, one for visible and ultraviolet, and three for the near infrared. The scheme includes Rayleigh scattering, absorption by water vapour, ozone $\left(\mathrm{O}_{3}\right)$, carbon dioxide $\left(\mathrm{CO}_{2}\right)$, methane $\left(\mathrm{CH}_{4}\right)$ and nitrous oxide $\left(\mathrm{N}_{2} \mathrm{O}\right)$. Water vapour is a prognostic variable. Ozone is 
interpolated in time from a monthly zonal mean climatology (Fortuin and Kelder, 1998). Carbon dioxide, methane and nitrous oxide are assumed to be uniformly mixed. Carbon dioxide estimates for the PE range from $300 \mathrm{ppm}$ to more than 2000 ppm before the PETM, and even higher concentrations during the PETM (Pearson and Palmer, 2000; Royer et al., 2001). Since we aim at simulating the PE background climate, we use a relatively low carbon dioxide concentration of $560 \mathrm{ppm}$, which is twice the pre-industrial value. There is no proxy available for methane nor for nitrous oxide. For simplicity, methane and nitrous oxide are set to pre-industrial values (concentrations given in Table 1).

Longwave radiation is computed in the Rapid Radiative Transfer Model (RRTM) developed by Mlawer et al. (1997). The RRTM scheme computes fluxes in the spectral range $10 \mathrm{~cm}^{-1}$ to $3000 \mathrm{~cm}^{-1}$. The computation is organised in 16 spectral bands and includes line absorption by water, carbon dioxide, ozone, methane, nitrous oxide, and aerosols. Aerosol distributions are prescribed following Tanré et al. (1984).

The cloud scheme consists of prognostic equations for water vapour, liquid and solid water, and bulk cloud microphysics. Cloud cover is computed diagnostically from relative humidity following Lohmann and Roeckner (1996).

We interpolate the orography from a $55 \mathrm{Ma}$ $2^{\circ} \times 2^{\circ}$ geography reconstructed by Bice and Marotzke (2001) (Fig. 1a). The standard version of ECHAM5 utilises a parameterisation developed by Lott and Miller (1997) to account for interactions between subgrid-scale orography (SSO) and the atmospheric flow. This SSO parameterisation needs the standard deviation, anisotropy, slope, orientation, minimum, maximum, and mean elevation of the orography for each gridpoint. Since we do not have that information for the PE, we switch the SSO parameterisation off.

For simplicity, we prescribe a globally homogeneous vegetation (parameters given in Table 1), which is characterised by a lower albedo compared to the pre-industrial average, a slightly larger leaf area index, and a larger forest fraction, consistent with a larger fraction of high-latitude, and dark, tropical forests (see Utescher and Mosbrugger, 2007, for an Eocene vegetation reconstruction). The leaf area index does not vary seasonally in the PE setup. We prescribe a surface roughness length that resembles the pre-industrial average over land. The soil and vegetation parameter settings are akin a present-day, woody savanna during its growing season (Hagemann et al., 1999; Hagemann, 2002). We prescribe no glaciers, which is consistent with paleo-reconstructions (Zachos et al., 2001; Sluijs et al., 2006).

River runoff is treated interactively in the atmosphere model, and the respective fresh water flux is passed to the ocean as part of the atmospheric freshwater flux field. In our PE setup, we assume that rivers flow along the surface geopotential height gradient but overleap valleys such that no lakes are formed.
Orbital parameters in our PE simulation are set to constant values (see Table 1). The longitude of perihelion, the obliquity, and the eccentricity as computed by Laskar et al. (2004) vary on timescales much shorter than the length of the PE period (Fig. 2). Moreover, Laskar et al. (2004) reported that their simulation of the orbital parameters becomes uncertain for more than 40 to $50 \mathrm{Ma}$ ago. We select a longitude of perihelion such that the Northern Hemisphere winter occurs in the aphelion (almost like today). The present-day obliquity and eccentricity are rather extreme values. For the PE, we select an obliquity and an eccentricity closer to the temporal average of the solution by Laskar et al. (2004, see Fig. 2).

\subsection{Ocean-sea ice general circulation model}

The Max-Planck-Institute Ocean Model (MPI-OM, here: version 1.2.0) is a $\mathrm{z}$-coordinate global GCM based on the primitive equations for a hydrostatic Boussinesq fluid with a free surface (Marsland et al., 2003). Scalar and vector variables are formulated on an orthogonal curvilinear C-grid (Arakawa and Lamb, 1977). Along-isopycnal diffusion is implemented following Griffies (1998). Horizontal tracer mixing by unresolved eddies is parameterised following Gent et al. (1995). For the vertical eddy viscosity and diffusion the Richardson-number dependent scheme of Pacanowski and Philander (1981) is applied. Since the Pacanowski-Philander (PP) scheme in its classical form underestimates the turbulent mixing close to the surface, an additional wind mixing parameterisation is included. In the presence of static instability, convective overturning is parameterised by greatly enhanced vertical diffusion. A bottom boundary layer slope convection scheme allows for an improved representation of the flow of statically unstable dense water over sills. The effect of ocean currents on surface wind stress is accounted for following Luo et al. (2005). The embedded sea ice model consists of sea ice dynamics following Hibler (1979) and zero-dimensional thermodynamics following Semtner (1976). For more details on MPI-OM and the embedded sea ice model see Marsland et al. (2003) and Jungclaus et al. (2006).

To apply MPI-OM to the PE, we include the PE bathymetry and generate an appropriate model grid. As for the orography in the atmospheric model, we interpolate the bathymetry from the reconstruction by Bice and Marotzke (2001). The MPI-OM grid structure allows for an arbitrary placement of the grid poles; we generate a grid with a gridNorth Pole on Paleo-Asia and a grid-South Pole on PaleoSouth America (Fig. 1b). This model grid has several advantages. Positioning the grid-poles over land removes the numerical singularities associated with the convergence of meridians at the geographical poles. Positioning the gridpoles on wide landmasses allows us to reduce the total number of gridpoints. Moreover, this setup yields a higher resolution of many small but important seaways (e.g., open North Atlantic, Central American Seaway, Tethys Seaway, 



Fig. 1. (a) PE orography interpolated on the Gaussian grid that corresponds to the T31 spectral truncation; displayed orography not spectrally filtered. (b) PE bathymetry as used in MPI-OM.
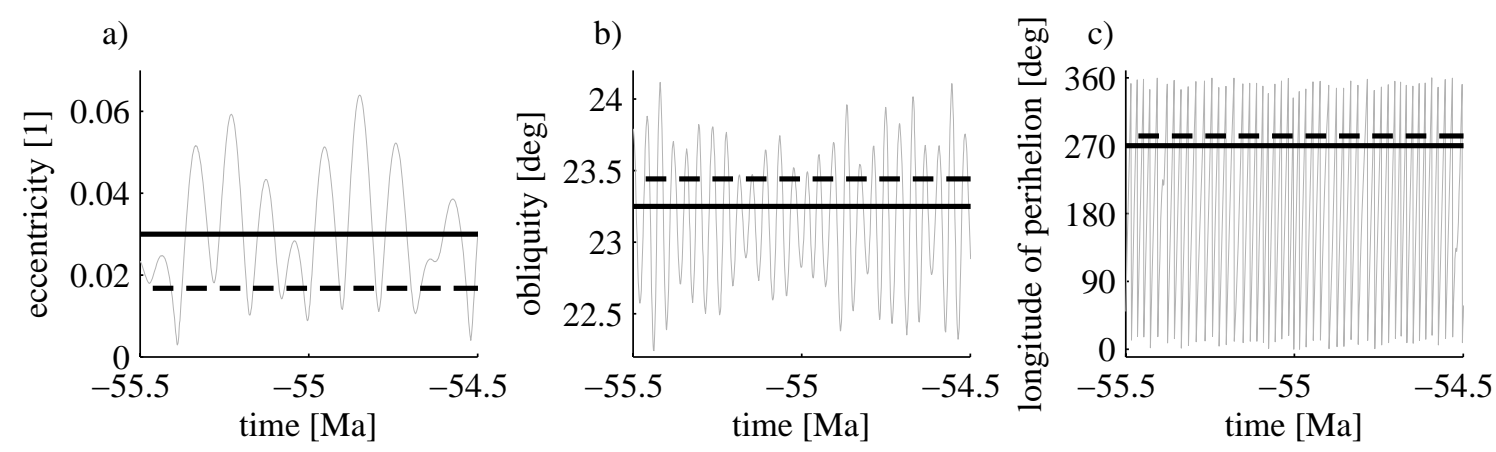

Fig. 2. (a) Eccentricity, (b) obliquity, and (c) longitude of perihelion as computed by Laskar et al. (2004) (thin grey line), constant values as used for the PE setup (heavy black), and pre-industrial values (heavy black, dashed; for the year $2000 \mathrm{AD}$ according to Berger, 1978, see also Table 1).

India-Eurasia gateway; Bice and Marotzke, 2002). The grid spacing varies between $70 \mathrm{~km}$ around South America and $430 \mathrm{~km}$ in the Pacific. We use 40 levels in the vertical, of which 9 levels are in the uppermost $100 \mathrm{~m}$ and 18 levels in the uppermost $500 \mathrm{~m}$.

\subsection{Spinup}

To approach the equilibrium PE climate state, we run the model for 2500 years. The atmosphere and the ocean are initialised at rest. The ocean is initialised at a potential temperature of $283 \mathrm{~K}$, and a salinity of $34.3 \mathrm{psu}$, which is 
Table 1. ECHAM5 input parameters as used in the PE model setup compared to those in the pre-industrial reference run (PR); FAO determines volumetric heat capacity and thermal diffusivity of soil; note that, while the PE land surface is homogeneous, the land surface parameters for PR are spatially variable; the PR values given here are mean values. The pre-industrial orbital parameters are given for the year $2000 \mathrm{AD}$ according to Berger (1978) while, actually, the orbital parameters in PR vary temporally according to VSOP87 (Variations Séculaire des Orbites Planétaires, Bretagnon and Francou, 1988).

\begin{tabular}{lcc}
\hline parameter & $P E$ & $P R$ \\
\hline carbon dioxide concentration $\left(p \mathrm{CO}_{2}\right)$ & $560 \mathrm{ppm}$ & $278 \mathrm{ppm}$ \\
methane concentration $\left(p \mathrm{CH}_{4}\right)$ & $0.8 \mathrm{ppm}$ & $0.65 \mathrm{ppm}$ \\
nitrous oxide concentration $\left(p \mathrm{~N}_{2} \mathrm{O}\right)$ & $0.288 \mathrm{ppm}$ & $0.27 \mathrm{ppm}$ \\
\hline total solar irradiance $\left(\mathrm{S}_{0}\right)$ & $1367 \mathrm{~W} \mathrm{~m}^{-2}$ & $1367 \mathrm{~W} \mathrm{~m}^{-2}$ \\
eccentricity of the Earth's orbit & 0.0300 & 0.0167 \\
obliquity or inclination of the Earth's axis & $23.25^{\circ}$ & $23.44^{\circ}$ \\
longitude of perihelion & $270^{\circ}$ & $283^{\circ}$ \\
\hline land surface background albedo & 0.16 & 0.25 \\
sea surface albedo & 0.07 & 0.07 \\
vegetation ratio & 0.6 & 0.4 \\
leaf area index (LAI) & 2.3 & 2.2 \\
forest fraction & 0.40 & 0.26 \\
maximum field capacity of soil (single bucket water height) & $1.2 \mathrm{~m}$ & $0.6 \mathrm{~m}$ \\
FAO soil data flag $(1 \sim$ sand, $3 \sim$ mud, 5 clay) & 3 & 2.6 \\
surface roughness length over land & $1.6 \mathrm{~m}$ & $1.6 \mathrm{~m}$ \\
\hline
\end{tabular}

approximately the salinity we would get in the present-day ocean if all glaciers melted completely. The atmosphere approaches its equilibrium after some 150 years, whereas in most ocean basins the transient phase lasts for about 1000 years. After 1000 years, the globally averaged temperatures even at the deepest levels only increase by less than $0.3 \mathrm{~K}$ per 1000 years (Fig. 3a).

The Arctic deep ocean takes especially long to equilibrate, since it is only connected to the other basins via shallow sills. Moreover, the Arctic is stratified due to fresh surface water that inhibits vertical mixing. After 2000 years, the Arctic deep ocean is 281 to $283 \mathrm{~K}$ warm and still warming by more than $1 \mathrm{~K}$ per 1000 years (Fig. 3b). The Arctic SST hardly shows a warming trend, despite the deep ocean warming.

\subsection{Pre-industrial reference simulation}

In this study, we compare the PE simulation to a 2200 year long ECHAM5/MPI-OM simulation with pre-industrial boundary conditions that has been initialised from Levitus data. We refer to this pre-industrial reference simulation as PR. The pre-industrial boundary conditions include the bathymetry, orography, greenhouse gas concentrations, soil and vegetation properties, and orbital parameters (Table 1). The pre-industrial boundary conditions also include the subgrid-scale orographic information; the SSO parameterisation in PR is switched on, while it is switched off in PE. Moreover, PR uses a modified physical parameterisation of friction and diffusion to improve the representation of the El Niño-Southern Oscillation (ENSO, see Jungclaus et al.,
2006), while PE uses the standard MPI-OM parameter settings as specified by Marsland et al. (2003). While the orbital parameters in PE are constant, the parameters in PR vary temporally according to VSOP87 (Variations Séculaire des Orbites Planétaires, Bretagnon and Francou, 1988, the first year of PR is 800 AD, the last year is 2999 AD). The philosophy behind this approach is to compare the PE simulation to an as good as possible representation of the pre-industrial climate.

An alternative approach to set up a pre-industrial reference would be to degrade the pre-industrial boundary conditions to the level of accuracy available for the PE (see, e.g., Huber et al., 2003), which would worsen the representation of the pre-industrial climate. Such a degradation would also include to switch off the SSO parameterisation. To test the effect of the SSO parameterisation, and to ensure that neither the ENSO-tuning nor the dynamic orbital parameters have a major effect on the pre-industrial climate, we perform a 400 year long pre-industrial sensitivity run. This sensitivity run $\left(\mathrm{PR}^{\prime}\right)$ restarts from $\mathrm{PR}$, it does not use the SSO parameterisation nor the ENSO-tuning, and it uses constant orbital parameters as specified in Table 1. Moreover, it uses the PE concentrations of nitrous oxide and methane (Table 1), and a carbon dioxide concentration of $280 \mathrm{ppm}$ (instead of $278 \mathrm{ppm}$ ). Hence, the difference between $\mathrm{PE}$ and $\mathrm{PR}^{\prime}$ is the land-sea mask and topography, the vegetation, the (now constant as in PE) orbital forcing, and the (now exactly) doubled $p \mathrm{CO}_{2}$. We find that the differences in the model setup between PR and $\mathrm{PR}^{\prime}$ lead to a global warming of approximately $0.8 \mathrm{~K}$ in $\mathrm{PR}^{\prime}$ compared to $\mathrm{PR}$. The warming is largest 
a) GLOBAL

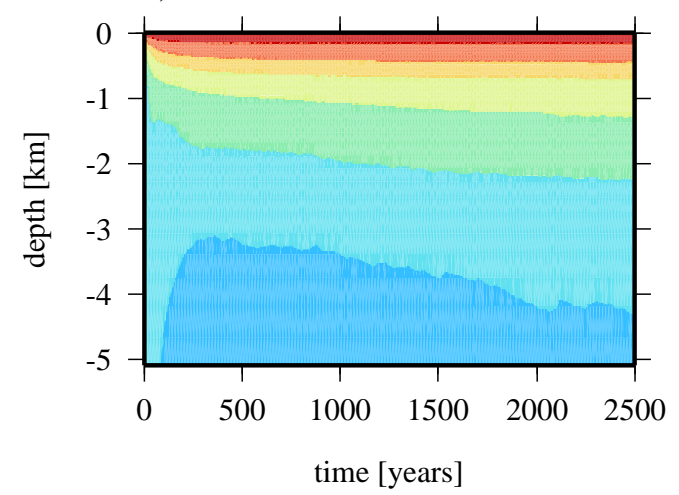

b) ARCTIC

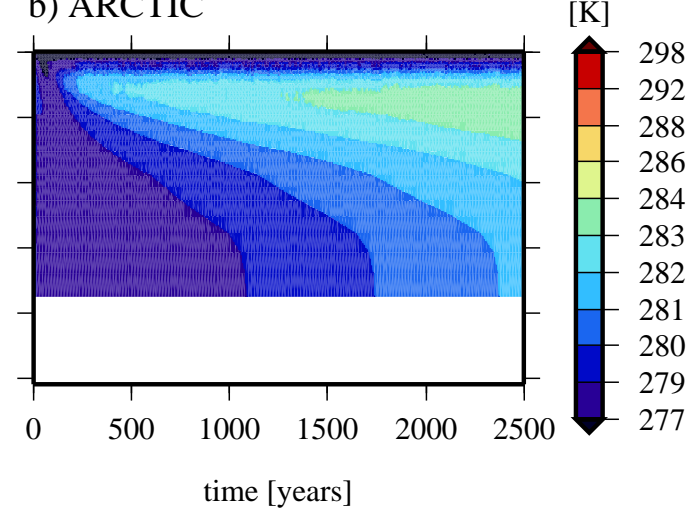

Fig. 3. Hovmöller diagram of the potential temperature in the PE simulation (50 year running mean) (a) averaged globally, and (b) averaged over the Arctic ocean.

at northern high latitudes, where it reaches up to $3 \mathrm{~K}$. However, the differences between $\mathrm{PR}$ and $\mathrm{PR}^{\prime}$ remain small compared to the differences between PE and PR. Using $\mathrm{PR}^{\prime}$ instead of PR would lead to a small modification of some quantitative results, but the general results and conclusions of this work are not affected.

\section{Simulated Paleocene/Eocene climate}

The aim of this section is to describe the simulated PE climate, to briefly compare it to proxy data, and to identify the main differences between PE and PR.

\subsection{Surface temperature}

The simulated PE Earth's surface is on average $297 \mathrm{~K}$ warm and basically ice-free. There is one small area in the Weddell Sea, and one small area north of proto-Greenland that do have a little bit of sea ice in a few, exceptionally cold winters. The sea ice fraction in these areas amounts to less than $0.1 \%$ with a sea ice thickness of less than $3 \mathrm{~mm}$.

The highest annual mean surface temperatures of 313 to $314 \mathrm{~K}$ occur in low altitude areas of South Asia, some areas in central South America, and Africa (Fig. 4). During local summers, surface temperatures reach up to $325 \mathrm{~K}$ in South Asia, $322 \mathrm{~K}$ in central South America, and $318 \mathrm{~K}$ in North Africa (temperatures are 200 year means of the warmest month).

The lowest annual mean surface temperatures of about $270 \mathrm{~K}$ occur over the Antarctic continent. Antarctic summer surface temperatures are around $295 \mathrm{~K}$ even at the coldest places. In the Northern Hemisphere, the lowest surface temperature of $271 \mathrm{~K}$ occurs in the Rocky Mountains, where monthly means vary between $261 \mathrm{~K}$ and $285 \mathrm{~K}$. The Arctic has the coldest summers on the PE globe; the warmest Arctic monthly mean SSTs only reach about $280 \mathrm{~K}$.
Local winter snow depths reach $1.2 \mathrm{~m}$ in the Rocky Mountains, $40 \mathrm{~cm}$ in Greenland, $30 \mathrm{~cm}$ on the Antarctic continent, and $20 \mathrm{~cm}$ in Siberia. During local summers all the snow melts away, there is no long-term snow accumulation.

\subsection{Comparison to proxy data}

We compare the simulated surface temperatures to proxy data from the period preceding the PETM (Figs. 4 and 5a). Most SST reconstructions are within the simulated seasonal variability of the zonal means.

One reconstruction differs very much from the simulated zonal mean SST: Sluijs et al. (2006) inferred Arctic SSTs of about $291 \mathrm{~K}$ from the biomarker TEX 86 . However, Sluijs et al. (2006) argue that the reconstruction may be skewed to summer SSTs. The simulated monthly mean Arctic SSTs vary between 276 and $280 \mathrm{~K}$. Thus the simulated Arctic surface is 11 to $13 \mathrm{~K}$ colder than inferred by Sluijs et al. (2006).

Note that annual mean sea surface temperatures in the proto Labrador Sea, which is close to the lower vertebrate findings of Estes and Hutchinson (1980), amount to about 290 K. According to Markwick (1998), the minimum thermal limit for crocodiles is a coldest-month mean temperature of 278.7 K. While the coldest-month Labrador Sea surface temperature amounts to more than $285 \mathrm{~K}$, the coldest-month land surface temperatures in the vicinity of the Labrador Sea fall just below $270 \mathrm{~K}$. North American continental temperatures east of the Rocky Mountains amount to more than $285 \mathrm{~K}$, and monthly means are above freezing all year round south of $55^{\circ} \mathrm{N}$ in that area. This relatively warm continental area matches the area where Markwick (1994) found most fossil crocodiles (Fig. 4).

\subsection{PE-PR temperature differences}

The PE surface is on average $9.4 \mathrm{~K}$ warmer than the PR surface (Table 2). We find a large high-latitude amplification 


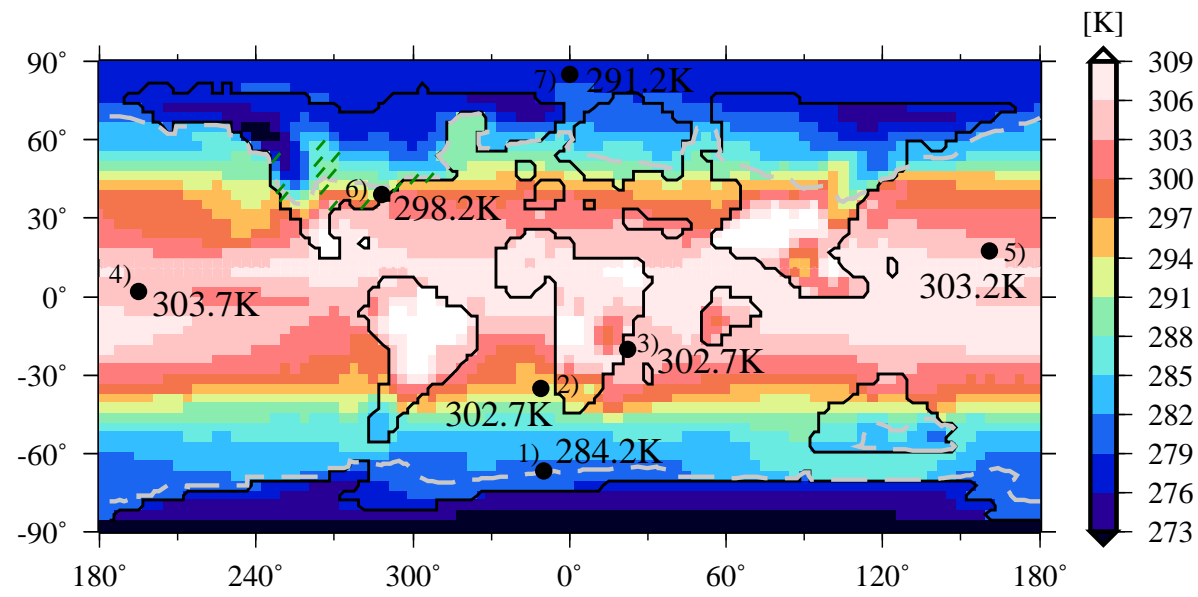

Fig. 4. Annual mean PE surface temperature (200 year mean) and comparison to proxy data. The black dots indicate SST estimates from proxy data for the pre-PETM published by 1) Thomas et al. (2002) based on $\delta^{18} \mathrm{O}$, 2) and 4) Tripati and Elderfield (2004) based on Mg/Ca ratios assuming the $\mathrm{Mg} / \mathrm{Ca}$ ratio of seawater to be $5.15 \mathrm{mmol} / \mathrm{mol}, 3)$ Pearson et al. (2007) based on $\delta^{18} \mathrm{O}$, 5) Zachos et al. (2003) based on TEX 86 , 6) Zachos et al. (2006) based on TEX 86 , 7) Sluijs et al. (2006) based on TEX 86 . The dashed grey line is the $278.7 \mathrm{~K}$-isoline of the simulated minimum monthly mean surface temperature ('crocodilian-survival-line'; Markwick, 1998); green dashes indicate the Eocene North American crocodilian distribution taken from Markwick (1994).

of this warming (Fig. 5b). The low-latitude zonal mean PE surface temperatures are about 5 to $8 \mathrm{~K}$ warmer than in PR, while northern high latitudes are warmer by up to $20 \mathrm{~K}$, and southern high latitudes are warmer by up to $40 \mathrm{~K}$. The SST PE-PR differences are smallest in the South Atlantic and North and South Pacific subtropical gyres at about $\pm 15^{\circ} \mathrm{N}$. The PE zonal mean SSTs are about $5 \mathrm{~K}$ higher at low latitudes, about $10 \mathrm{~K}$ higher in the Southern Ocean, and up to $12 \mathrm{~K}$ higher at $45^{\circ} \mathrm{N}$.

While the surface temperature PE-PR difference increases towards higher latitudes, the SST PE-PR difference north of $50^{\circ} \mathrm{N}$ decreases towards the North Pole. This difference occurs because the SSTs in PR cannot fall below the freezing point of sea water. Over land, the surface temperature as defined in ECHAM5 is computed from the energy balance at the land surface-atmosphere interface. It is not identical but close to the $2 \mathrm{~m}$ air temperature. Over water, the surface temperature in ECHAM5 is identical to the SST, which in MPI$\mathrm{OM}$ is the mean temperature of the uppermost, $12 \mathrm{~m}$ thick level. In the presence of sea ice, the surface temperature is defined as the temperature at the sea ice-atmosphere interface. Note that PE is basically sea ice free (Sect. 3.1), while PR has sea ice both in the northern and in the Southern Hemisphere. At least $80 \%$ of the PR Arctic ocean remain sea-ice covered all year round, the average sea ice thickness amounts to about $3 \mathrm{~m}$. During the Northern Hemisphere winter, the sea ice extends to about $50^{\circ} \mathrm{N}$. The Antarctic sea ice border in the Southern Hemisphere winter reaches about $65^{\circ} \mathrm{S}$, most of the Antarctic sea ice is less than $1 \mathrm{~m}$ thick.

\subsection{Differences in the hydrological cycle}

Compared to PR, the PE hydrological cycle is intensified by about $25 \%$ (Fig. 6). Convective precipitation is higher by about $0.3 \mathrm{~m}$ per year (20 to $30 \%$ ) at low latitudes between $\pm 10^{\circ} \mathrm{N}$. Also, convective precipitation is higher by about $0.2 \mathrm{~m}$ per year at latitudes higher than $30^{\circ}$, which is remarkable since there is hardly any convective precipitation at high latitudes in PR. This is consistent with the hypothesis that convective clouds cause high-latitude warming in PE (Abbot and Tziperman, 2008). The PE peak large-scale precipitation is higher than in PR by more than $0.2 \mathrm{~m}$ per year, and it is shifted to higher latitudes. Snowfall is reduced and occurs at higher latitudes only. Evaporation is enhanced by -0.2 to $-0.4 \mathrm{~m}$ per year with the largest absolute changes in the Northern Hemisphere low latitudes, and the largest relative changes at the poles.

\subsection{Meridional heat transport}

The total PE and PR atmospheric heat transports are fairly symmetric about the equator, with maximum poleward transports of about $5.3 \mathrm{PW}\left(1 \mathrm{PW}=10^{15} \mathrm{~W}\right)$ at $\pm 40^{\circ} \mathrm{N}$. We find that the meridional transport of latent heat is increased in PE compared to PR, especially the poleward transports around $\pm 45^{\circ} \mathrm{N}$, and the equatorward transport in the northern Hadley cell (around $15^{\circ} \mathrm{N}$ ). The meridional transports of dry static energy reduce such that the total atmospheric heat transport in PE and PR hardly differ from each other (Fig. 7a).

The maximum northward oceanic heat transport in PE is about $0.5 \mathrm{PW}$ smaller than in PR. We find that most of this 

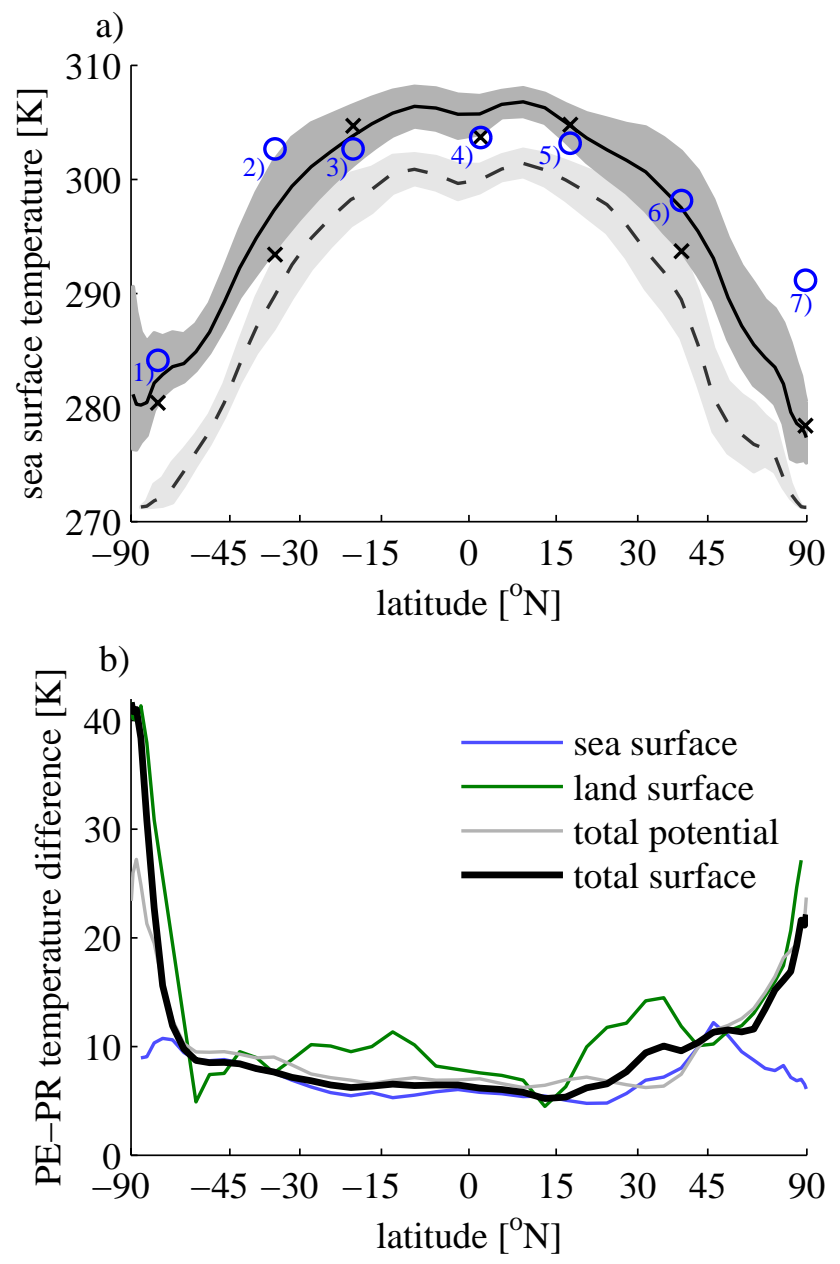

Fig. 5. (a) Zonal mean annual mean sea surface temperature (SST) in PE (solid), and in PR (dashed); the shading indicates the seasonal variability of the 200-year climatology (differences between the warmest and coldest months); blue circles are SST estimates from proxy data for the pre-PETM published by 1) Thomas et al. (2002) based on $\delta^{18} \mathrm{O}, 2$ ) and 4) Tripati and Elderfield (2004) based on $\mathrm{Mg} / \mathrm{Ca}$ ratios assuming the $\mathrm{Mg} / \mathrm{Ca}$ ratio of seawater to be $5.15 \mathrm{mmol} / \mathrm{mol}, 3)$ Pearson et al. (2007) based on $\left.\delta^{18} \mathrm{O}, 5\right) \mathrm{Za}$ chos et al. (2003) based on TEX 86,6 ) Zachos et al. (2006) based on $\mathrm{TEX}_{86}$, 7) Sluijs et al. (2006) based on $\mathrm{TEX}_{86}$; the black crosses indicate the simulated SSTs at the paleo-locations of the reconstructions. (b) Annual mean temperature differences between PE and PR for the total surface (heavy, black), the dry potential temperature at the global mean surface pressure of $985.5 \mathrm{hPa}$ (grey), only land surface (green), and only sea surface (blue). The horizontal scale is such that the spacing between the latitudes is proportional to the area of the Earth's surface between them, i.e., is linear in the sine of the latitude.

difference is due to a decreased heat transport by the meridional overturning circulation (MOC, see Fig. 7b). However, the poleward oceanic gyre heat transport across $45^{\circ} \mathrm{N}$ is also reduced by almost $0.4 \mathrm{PW}$ in PE compared to PR. We will

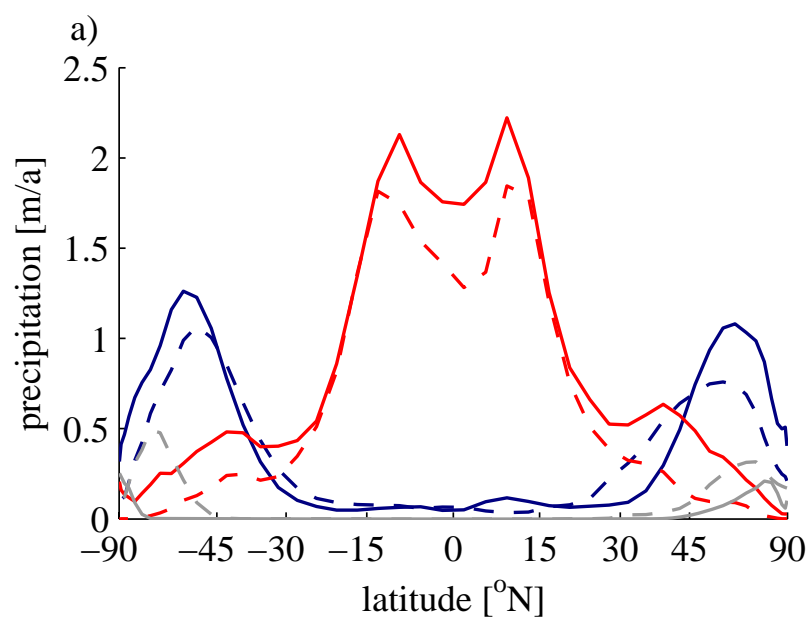

b)

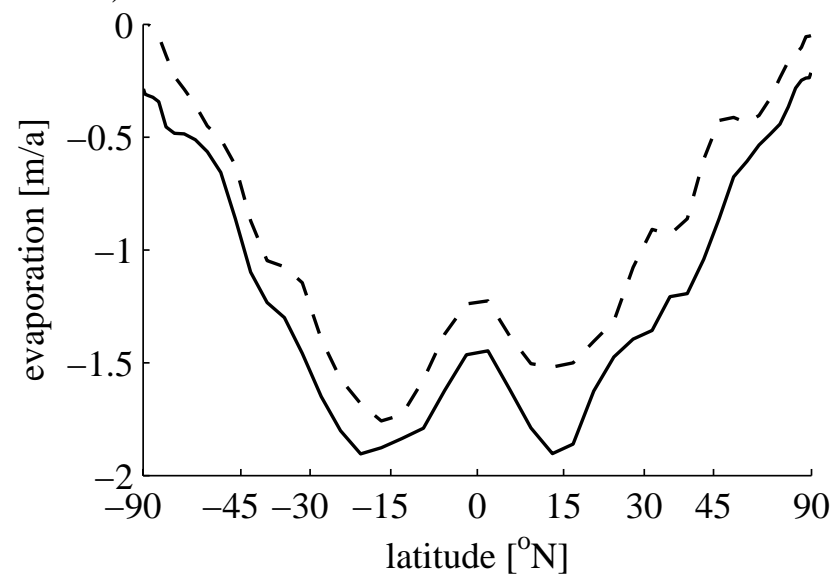

Fig. 6. (a) Zonal mean convective precipitation (red), large scale precipitation (dark blue), and snowfall (grey); (b) zonal mean evaporation; both precipitation and evaporation are diagnosed from the last 200 years of PE (solid) and PR (dashed). The horizontal scale is linear in the sine of the latitude.

estimate the effect of the PE-PR heat transport differences on the PE-PR zonal mean surface temperature difference in Sect. 4.2.

\section{Analysis of mechanisms causing PE-PR differences}

The aim of this section is to isolate and quantify the most important mechanisms that lead to the surface temperature differences between PE and PR.

\subsection{Zero-dimensional energy balance model}

The Earth's surface in PE is on average $9.4 \mathrm{~K}$ warmer than in PR (Table 2). To better understand this large difference in surface temperature, we first compare the planetary albedos and the effective longwave emissivities in PE to those in 
Table 2. Some key global mean climate parameters; while $\tau_{s}$ is the global mean surface temperature as diagnosed from the GCM, $\tau_{s, e b m}$ is the EBM derived surface temperature (see Eq. 1) using the GCM diagnosed planetary albedo $\alpha$ and effective longwave emissivity $\epsilon, \tau_{s, e b m, c}$ is computed from the clear sky values $\alpha_{c}$ and $\epsilon_{c}$.

\begin{tabular}{lcc}
\hline parameter & $P E$ & $P R$ \\
\hline surface temperature $\tau_{s}$ & $297.0 \mathrm{~K}$ & $287.6 \mathrm{~K}$ \\
mean surface pressure & $985.5 \mathrm{hPa}$ & $985.5 \mathrm{hPa}$ \\
mean sea level pressure (SLP) & $1001 \mathrm{hPa}$ & $1012 \mathrm{hPa}$ \\
potential temperature at SLP & $298.4 \mathrm{~K}$ & $289.9 \mathrm{~K}$ \\
planetary albedo $\alpha$ & 0.292 & 0.318 \\
clear sky planetary albedo $\alpha_{c}$ & 0.133 & 0.173 \\
surface albedo $\alpha_{s}$ & 0.094 & 0.137 \\
effective emissivity $\epsilon$ & 0.541 & 0.585 \\
clear sky effective emissivity $\epsilon_{c}$ & 0.608 & 0.658 \\
surface temperature $\tau_{s, e b m}(0-\mathrm{D})$ & 298.0 & 289.5 \\
surface temperature $\tau_{s, e b m}(1-\mathrm{D})$ & 297.2 & 287.9 \\
surface temperature $\tau_{s, e b m, c}(0-\mathrm{D})$ & 304.9 & 295.7 \\
longwave cloud radiative forcing $(\mathrm{CRF})$ & $29.6 \mathrm{Wm}^{-2}$ & $28.8 \mathrm{Wm}^{-2}$ \\
upward longwave radiation at the surface $L W_{S}^{\uparrow}$ & $-445 \mathrm{~W} \mathrm{~m}^{-2}$ & $-395 \mathrm{Wm}^{-2}$ \\
shortwave CRF & $-54.3 \mathrm{Wm}^{-2}$ & $-49.6 \mathrm{Wm}^{-2}$ \\
total cloud cover & 0.576 & 0.617 \\
vertically integrated water vapour & $45.3 \mathrm{~kg} \mathrm{~m}^{-2}$ & $25.5 \mathrm{~kg} \mathrm{~m}^{-2}$ \\
spectrally filtered surface height h & $141 \mathrm{~m}^{-2}$ & $231 \mathrm{~m}^{-2}$ \\
\hline
\end{tabular}

PR. The PE planetary albedo is smaller by 0.026 (Table 2); less shortwave radiation is reflected by the atmosphere. This causes PE to be warmer than PR. The PE effective longwave emissivity is smaller by 0.044 ; the fraction of the longwave radiation emitted at the surface and leaving the top of the atmosphere is reduced. This also causes PE to be warmer than PR.

To quantify these effects, we apply a zero-dimensional (0D) energy balance model (EBM) that equates the incoming shortwave radiation and outgoing longwave radiation for a grey atmosphere:

$\frac{S_{0}}{4}(1-\alpha)=\epsilon \sigma \tau_{s, e b m}^{4}$

where $\tau_{s, e b m}$ is the surface temperature predicted by the 0 -D EBM, $S_{0}=1367 \mathrm{Wm}^{-2}$ the total solar irradiance, and $\sigma=5.67 \cdot 10^{-8} \mathrm{Wm}^{-2} \mathrm{~K}^{-4}$ the Stefan-Boltzmann constant. The factor $1 / 4$ accounts for the difference between the area of the circular Earth profile in the sunshine, and the area of the spherical Earth. We derive the planetary albedo $\alpha$ and the effective longwave emissivity $\epsilon$ from the globally averaged radiative fluxes in our coupled GCM

$\alpha=\frac{S W_{t}^{\uparrow}}{S W_{t}^{\downarrow}}, \epsilon=\frac{L W_{t}^{\uparrow}}{L W_{s}^{\uparrow}}$

where $S W_{t}^{\uparrow}$ and $S W_{t}^{\downarrow}$ are the upward and downward shortwave fluxes at the top of the atmosphere, and $L W_{t}^{\uparrow}$ and $L W_{s}^{\uparrow}$ are the upward longwave fluxes at the top of the atmosphere and the surface, respectively (Smith et al., 2006).
The 0-D EBM (1), fed with these albedos and emissivities, yields surface temperatures of $298.0 \mathrm{~K}$ and $289.5 \mathrm{~K}$ for the PE and PR simulations, respectively (Table 2). These temperatures are off the general circulation model (GCM) temperatures by less than $2 \mathrm{~K}$. The mismatch between the global mean surface temperatures from the 0-D EBM and those diagnosed from the GCM mostly arises from the meridional averaging of the albedo and the emissivity (this will become clear in Sect. 4.2). Still, the 0-D EBM temperature difference of about $8.5 \mathrm{~K}$ compares relatively well to the $9.4 \mathrm{~K}$ temperature difference in the GCM. According to the 0-D EBM, about $5.7 \mathrm{~K}$ of the warming are due to the reduced emissivity of longwave radiation, and about $2.8 \mathrm{~K}$ are due to the reduced planetary albedo (Fig. 8).

The PE-PR planetary albedo difference is a consequence of the smaller PE surface albedo especially at high latitudes, and due to cloud effects in the subtropics (Fig. 9 and Sect. 4.3). Notice that clouds at high latitudes diminish the effect of the PE-PR surface albedo difference (Sect. 4.3). The large zonal mean PE-PR surface albedo differences at high latitudes is in part caused by our assumption that there are no glaciers in PE. The other main factor is that PE, in contrast to PR, is basically sea ice free. Moreover, there is less high-latitude snowfall in PE compared to PR (Sect. 3.1). 


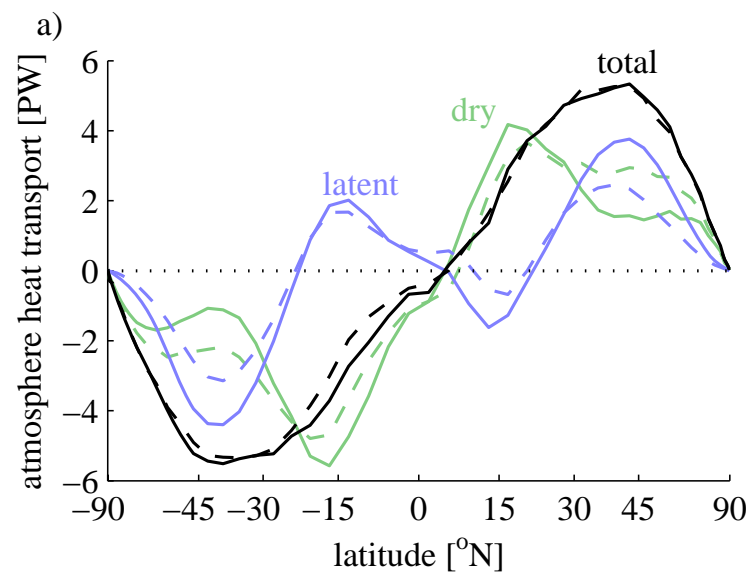

b)

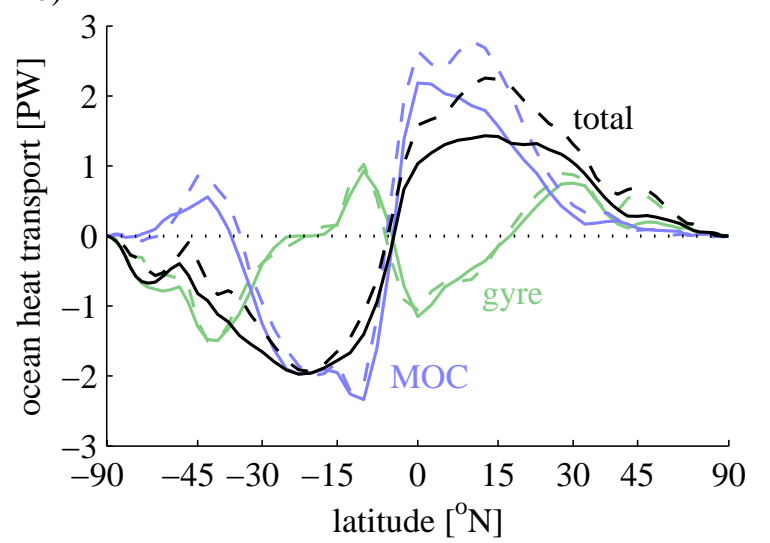

Fig. 7. (a) Zonally integrated meridional heat transport in the atmosphere due to the advection of dry air (green), due to the advection of moisture/latent heat (blue), and the sum (black), for PE (solid) and PR (dashed), computed from the last 100 years of each run with 6 hourly instantaneous sampling; (b) zonally integrated meridional ocean heat transport due to the meridional overturning circulation (MOC, blue), due to the gyre circulation (green), and the sum (black), for PE (solid) and PR (dashed), computed from monthly means of the last 1000 years of each run. The horizontal scale is linear in the sine of the latitude.

\subsection{One-dimensional energy balance model}

To assess the effect of the latitudinal inhomogeneity of the emissivity, albedo, and heat transport differences between PE and PR (Figs. 7 and 9), we extend the 0-D EBM (1) to the meridional dimension:

$S W_{t}^{\downarrow}(\phi)[1-\alpha(\phi)]-\frac{1}{2 \pi R^{2} \cos \phi} \frac{\partial F(\phi)}{\partial \phi}=\epsilon(\phi) \sigma \tau_{s, e b m}^{4}(\phi)(3)$

where $\phi$ is the latitude, $R$ the radius of the Earth, $S W_{t}^{\downarrow}(\phi)$ the zonal mean downward shortwave radiation at the top of the atmosphere, $\alpha(\phi)$ the zonal mean planetary albedo, $\epsilon(\phi)$ the zonal mean emissivity, $F(\phi)$ the total meridional heat trans-

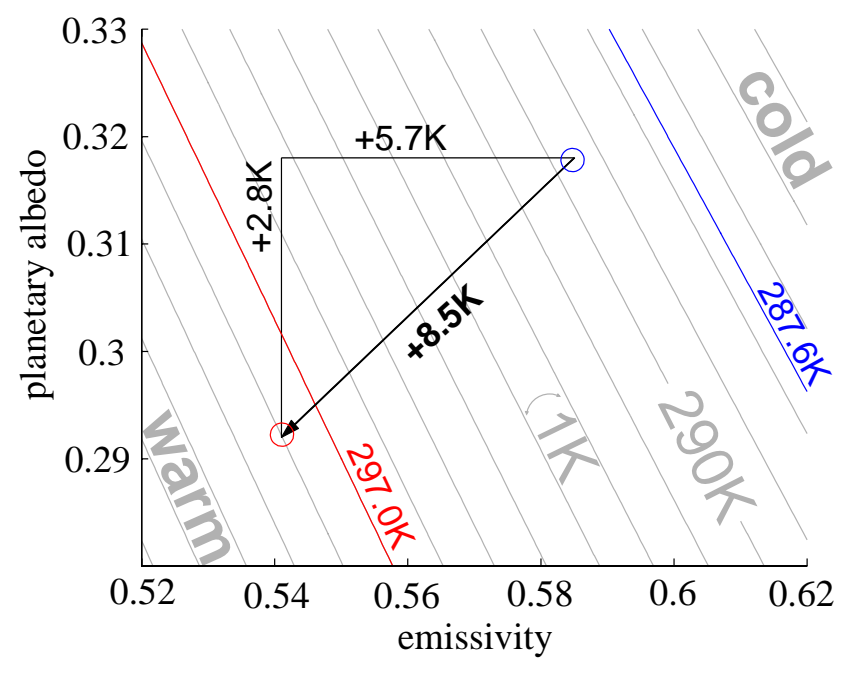

Fig. 8. Using the EBM to trace back the temperature difference between PE and PR to albedo and emissivity changes in the GCM; grey lines are contour lines of the EBM-predicted temperature for certain emissivities and albedos, contour intervals are $1 \mathrm{~K}$; the red and blue lines are the GCM-diagnosed temperatures for PE and PR, respectively; the circles are the surface temperatures predicted by the EBM using the GCM-diagnosed emissivities and albedos; the black arrow indicates the EBM-predicted PE-PR temperature difference; the black lines are auxiliary lines to estimate the albedoand emissivity-caused temperature difference separately.

port, and $\tau_{s}(\phi)$ the one-dimensional (1-D) EBM-predicted zonal mean surface temperature.

As in Sect. 4.1 for the 0-D EBM, we now fit this 1-D EBM to the GCM simulations PE and PR. To this end, we diagnose the zonal mean downward top-of-atmosphere shortwave radiation, the emissivity, and the albedo from the GCM simulations PE and PR, respectively. To compute the divergence of the total meridional heat transport $\frac{\partial}{\partial \phi} F(\phi)$, we diagnose the net shortwave plus longwave radiative flux at the top of the atmosphere; in other words, we compute the implied atmosphere plus ocean meridional heat transport divergence:

$\frac{\partial F(\phi)}{\partial \phi}=-2 \pi R^{2} \cos \phi\left(S W_{t}^{\mathrm{net}}(\phi)+L W_{t}^{\mathrm{net}}(\phi)\right)$

where $S W_{t}^{\text {net }}(\phi)$ and $L W_{t}^{\text {net }}(\phi)$ are the zonal mean net (downward is positive) top-of-atmosphere shortwave and longwave radiative fluxes, respectively.

We apply these diagnosed emissivities, albedos, and heat fluxes to the 1-D EBM to compute the zonal mean surface temperatures $\tau_{s, e b m}(\phi)$ for PE and PR, respectively. The resulting 1-D EBM-predicted zonal mean PE and 
a)

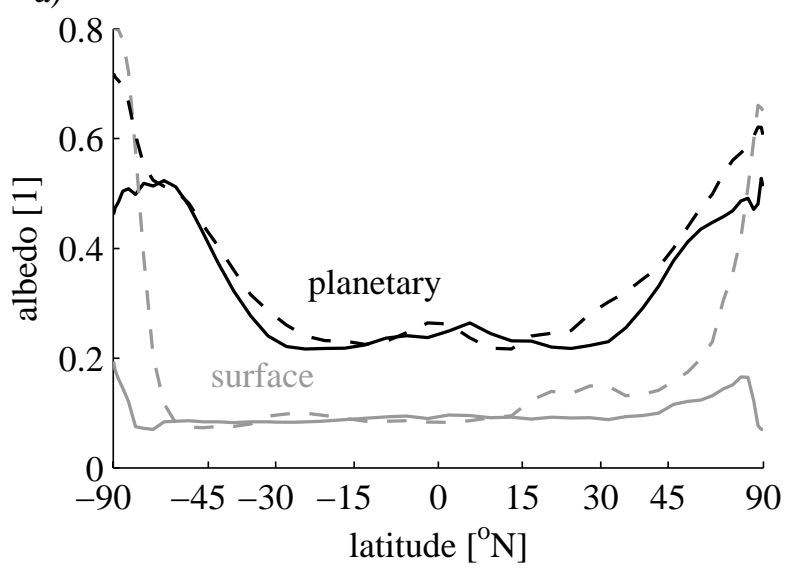

b)

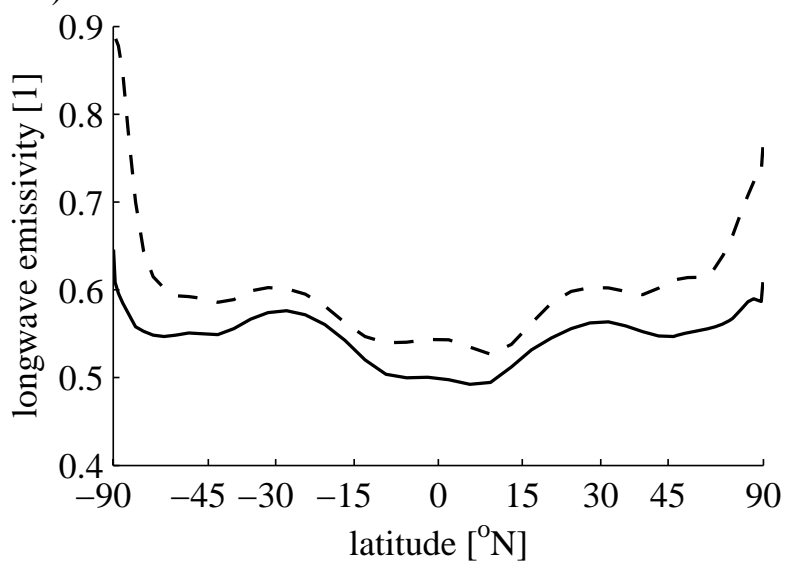

c)

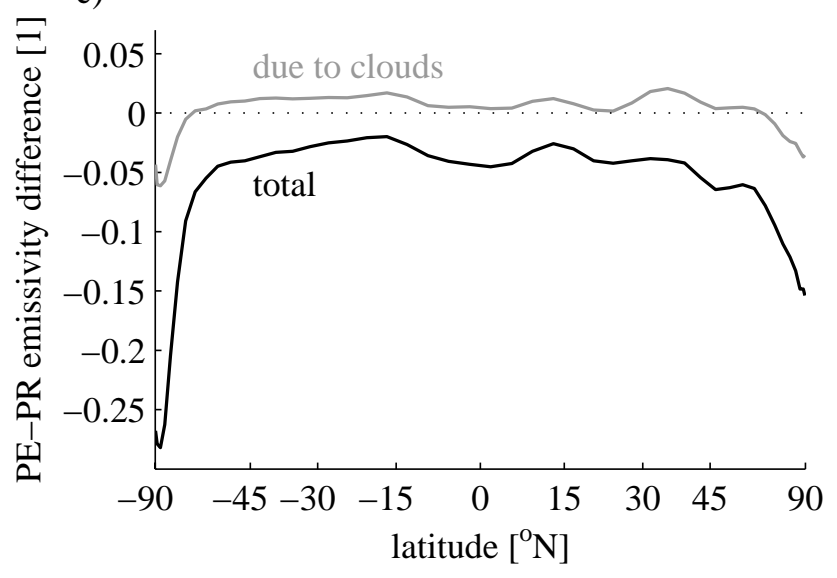

Fig. 9. (a) Zonal mean planetary (black) and surface (grey) albedo, for PE (solid) and PR (dashed), (b) effective longwave emissivity for PE (solid) and PR (dashed), and (c) PE-PR emissivity change (black) and PE-PR emissivity change due to clouds (grey) diagnosed from the difference between the full sky and clear sky emissivities. The horizontal scale is linear in the sine of the latitude.
PR surface temperatures $\tau_{s, e b m}(\phi)$ are very similar to the GCM-diagnosed surface temperatures $\tau_{s}(\phi)$ (Fig. 10a). The 1-D EBM predicts a PE-PR zonal mean surface temperature difference similar to the GCM-diagnosed PE-PR zonal mean surface temperature difference (Fig. 10b). The meridionally averaged 1-D EBM surface temperatures for PE and PR are only about $0.2 \mathrm{~K}$ warmer than the respective globally averaged GCM surface temperatures. Since the 1-D EBM fits very well to the GCM results, the mismatch between the 0D EBM and the GCM results as described in Sect. 4.1 must be due to the meridional averaging of the emissivity and the albedo, and due to the lack of meridional heat transport. The 1-D-EBM-predicted global mean PE-PR surface temperature difference amounts to $9.3 \mathrm{~K}$, which is very close to the GCMpredicted PE-PR temperature difference of $9.4 \mathrm{~K}$ (Table 2).

To isolate the contributions of the PE-PR albedo, emissivity, heat transport, and orbital forcing differences to the total PE-PR zonal mean surface temperature difference, we compute the EBM-predicted zonal mean surface temperature with either the albedo, the emissivity, the heat transport, or the orbital forcing diagnosed from PE and the other diagnostics from PR, and subtract the EBM-predicted PR zonal mean surface temperature (Fig. 10b). According to the 1-D EBM, 6.2 K (about 2/3) of the total global mean temperature difference $(9.3 \mathrm{~K})$ are due to the PE-PR longwave emissivity difference, and $2.8 \mathrm{~K}$ are due to the PE-PR planetary albedo difference (about 1/3). This confirms the results of the 0-D EBM (Sect. 4.1). The largest effect of the PE-PR emissivity difference on the zonal mean surface temperature occurs at high latitudes (Fig. 10b). Note that the PE-PR emissivity difference - especially in the Antarctic - is linked to surface elevation differences (Sect. 4.4). The effect of the PE-PR planetary albedo differences on the zonal mean surface temperature exhibits relatively large meridional variations. According to the 1-D EBM, the albedo-reduction due to the removal of the polar ice-caps in PE leads to a local surface warming of up to $10 \mathrm{~K}$ (Fig. 10b). Compared to PR, the PE surface albedo is not only smaller at high latitudes, but also around $30^{\circ} \mathrm{N}$ (Fig. 9a). This reduced PE albedo is, first, due to the lack of the bright Sahara, and, second, due to the lack of the Himalaya with its glaciers and snow cover. According to the 1-D EBM, these surface albedo changes in combination with changes of the shortwave cloud radiative effect (CRF) lead to an up to $7.4 \mathrm{~K}$ warmer zonal mean PE surface temperature around $30^{\circ} \mathrm{N}$ compared to PR. The smaller planetary albedo in $\mathrm{PE}$ around $30^{\circ} \mathrm{S}$ (Fig. 9a) locally causes an about $4 \mathrm{~K}$ warmer surface in PE compared to PR. Because the PE-PR surface albedo difference at $30^{\circ} \mathrm{S}$ is negligible, the planetary albedo difference at that latitude is mostly due to the reduced (negative) shortwave CRF in PE compared to PR (Sect. 4.3). The 1-D EBM also reveals that PE-PR heat transport differences do have large local effects on the surface temperature, but they hardly affect the average pole-toequator temperature gradient (Fig. 10b). 
a)
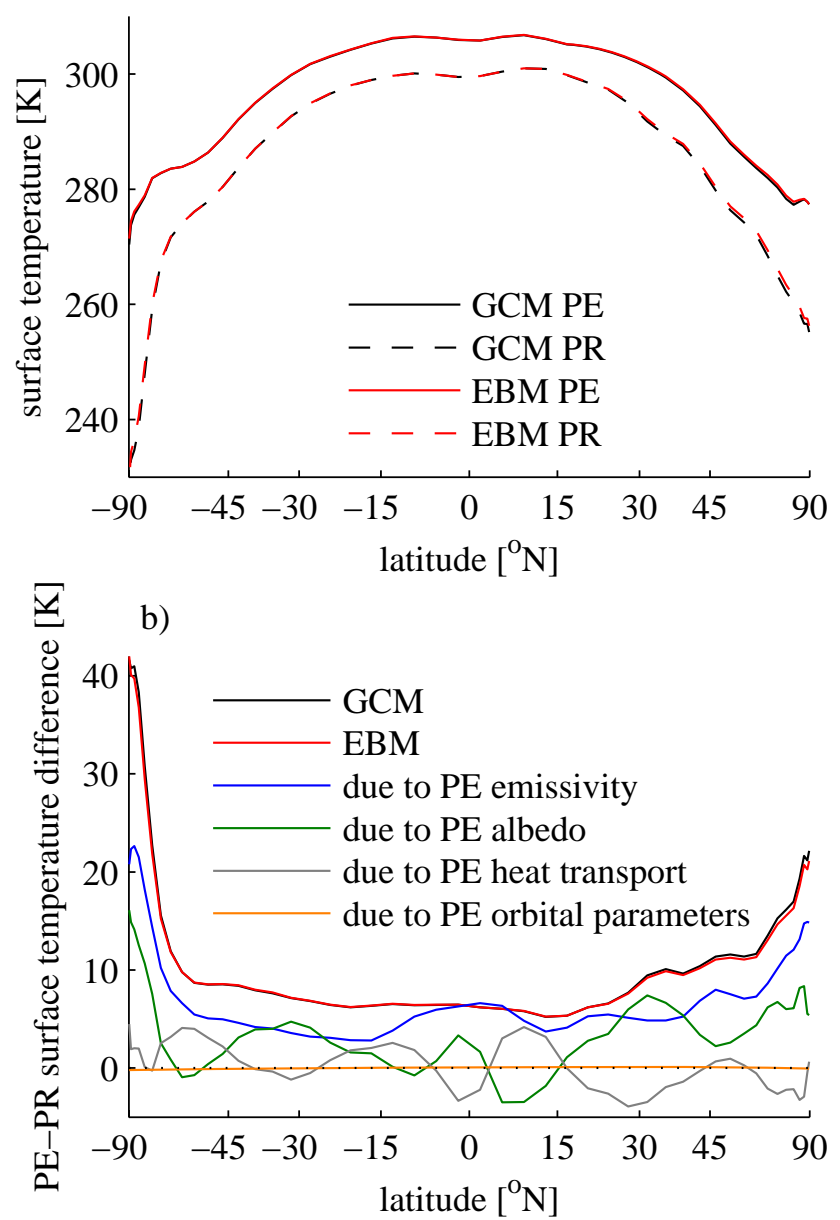

Fig. 10. (a) Zonal mean surface temperatures for PE (solid) and PR (dashed) as computed with the 1-D EBM (red) and directly diagnosed from the GCM (black). (b) Zonal mean PE-PR surface temperature difference as diagnosed from the GCM (black), and as computed from the 1-D EBM (red); the blue, green, grey, and orange lines indicate the temperature differences due to the PEPR emissivity difference, the planetary albedo difference, the heat transport difference, and the orbital forcing difference, respectively, computed using the 1-D EBM (3).

\subsection{Cloud radiative effect}

To estimate the effect of clouds in both GCM simulations, we first apply the 0-D EBM (1). This time, however, we use the clear sky radiative fluxes to compute the clear sky albedo $\alpha_{c}$ and clear sky effective longwave emissivity $\epsilon_{c}$

$\alpha_{c}=\frac{S W_{t, c}^{\uparrow}}{S W_{t}^{\downarrow}}, \epsilon_{c}=\frac{L W_{t, c}^{\uparrow}}{L W_{s}^{\uparrow}}$

where $S W_{t, c}^{\uparrow}$ is the upward clear sky shortwave flux, and $L W_{t, c}^{\uparrow}$ is the upward clear sky longwave flux at the top of the atmosphere. Note that the surface emits longwave radiation depending on the surface temperature, no matter what the cloudiness. The clear sky fluxes in ECHAM5 are computed assuming that there are no clouds; the difference between the albedos / emissivities computed from the clear sky and full sky fluxes thus yields the effect of clouds.

We find that clouds cause a $1 \mathrm{~K}$ stronger cooling in PE than in PR (namely $6.5 \mathrm{~K}$ compared to $5.5 \mathrm{~K}$, see Fig. 11). The reason for this stronger cooling is that clouds in $\mathrm{PE}$ have a larger effect on the albedo than clouds in PR. The planetary albedo increase due to clouds amounts to 0.159 in PE and only 0.145 in PR. By multiplication with $S_{0} / 4$, this translates into a shortwave CRF of $-54.3 \mathrm{Wm}^{-2}$ in PE compared to $-49.6 \mathrm{Wm}^{-2}$ in PR. Note that this larger negative shortwave CRF in PE occurs despite a reduced total cloud cover (Table 2). Even though the cloud cover is reduced, the shortwave effect of the clouds is larger in PE because the surface is darker. According to the 0-D EBM, the PE shortwave CRF causes a cooling of 15.0 or $15.5 \mathrm{~K}$, depending on whether we change the albedo or the emissivity first (black auxiliary lines in Fig. 11 are only drawn for emissivity decrease first). The pre-industrial shortwave CRF causes a cooling of 13.9 or $14.3 \mathrm{~K}$. The difference of 0.7 to $1.6 \mathrm{~K}$ is reduced by about $0.2 \mathrm{~K}$ due to a larger positive longwave CRF for PE $\left(29.6 \mathrm{Wm}^{-2}\right.$ compared to $\left.28.8 \mathrm{Wm}^{-2}\right)$. This larger longwave CRF in PE occurs despite a smaller cloud-induced emissivity change in PE compared to PR, because the absolute amount of longwave radiation emitted from the surface is much larger in PE than in PR $\left(445 \mathrm{Wm}^{-2}\right.$ compared to $395 \mathrm{Wm}^{-2}$, Table 2).

Note that the global mean PE-PR emissivity difference due to cloud cover differences is small only because the larger emissivity-effect of clouds at high latitudes in PE compared to PR is compensated by a smaller emissivity-effect of clouds at low latitudes (grey line in Fig. 9c). According to the 1-D EBM, the larger high-latitude and smaller low-latitude longwave CRF in PE compared to PR (Fig. 12a) lead to a reduction of the pole-to-equator temperature gradient by about $5 \mathrm{~K}$ (Fig. 12b).

On the other hand, clouds reduce the effect of the large high-latitude PE-PR surface albedo difference (Fig. 9a). The negative shortwave CRF at high latitudes in PE is larger than in PR, which, according to the 1-D EBM, causes the PE high latitudes to be up to $15 \mathrm{~K}$ colder than the PR high latitudes (Fig. 12b). Even though the surface albedo in the subtropics especially in the Southern Hemisphere in PE hardly differs from that in PR, the planetary albedo in the subtropics is significantly smaller in PE than in PR (Figure 9a). This smaller subtropical shortwave CRF in PE compared to PR (Fig. 12a) leads to almost $3 \mathrm{~K}$ warmer subtropics in PE compared to PR (Fig. 12b). 


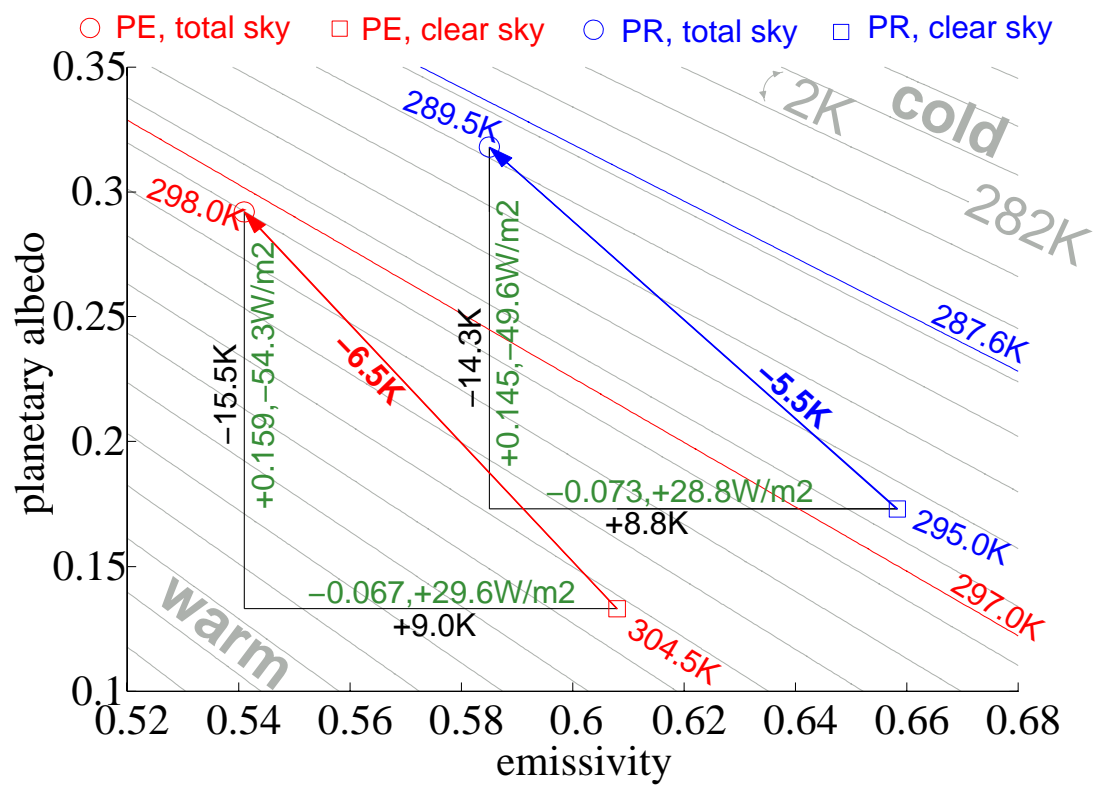

Fig. 11. Using the 0-D EBM (1) to estimate the effect of clouds on the PE-PR temperature difference; grey lines are contour lines of the 0-D EBM-predicted temperature, contour intervals are $2 \mathrm{~K}$; the red and blue lines are the GCM-diagnosed temperatures for PE and PR, respectively; the circles are the temperatures as computed from the 0-D EBM using the GCM-diagnosed full sky emissivities and albedos; the squares are 0-D EBM temperatures computed for the GCM-diagnosed clear sky emissivities and albedos; the red and blue arrows indicate the cooling due to clouds in PE and PR, respectively; the black lines are auxiliary lines to decompose the temperature differences into differences caused by albedo and emissivity; green numbers are emissivity and albedo changes due to clouds and the according cloud radiative forcing.

\subsection{Topographic differences}

Some of the regional PE-PR surface temperature differences are caused by topographic height differences. To quantify this effect, we compare the PE-PR surface temperature difference to the potential temperature difference. We compute the potential temperatures at the global mean surface pressure, assuming a dry adiabatic lapse rate of $9.8 \mathrm{~K}(\mathrm{~km})^{-1}$. The largest topographic effects occur in Antarctica, where the lower PE orography accounts for a zonal mean surface warming of up to $15 \mathrm{~K}$, and at the latitudes of the present day Himalaya, where it accounts for a zonal mean surface warming of about $3 \mathrm{~K}$ (compare solid black to grey line in Fig. 5b). The lower and consequently warmer Antarctic and Himalayan surface in PE emits more longwave radiation, while the emitted longwave radiation at the top of the atmosphere does not change under the assumption of a constant lapse rate. Hence, such a local reduction of the elevation leads to a reduced longwave emissivity. However, this direct effect on the longwave emissivity is only one consequence of the topographic differences. The lower and therefore warmer surface may also be less snow-covered. This positive albedo effect would lead to an additional warming. Moreover, if the topographic height is reduced, there is more room for clouds potentially effecting both the longwave emissivity and the planetary albedo.
The global mean spectrally averaged surface height in PE is about $90 \mathrm{~m}$ lower than in PR (Table 2). The global mean $\mathrm{PE}$ and PR potential temperatures at the respective mean sea level pressures differ by $0.9 \mathrm{~K}$ less than the global mean surface temperatures. However, since the global mean surface pressure in ECHAM5 is prescribed at $985.5 \mathrm{hPa}$ (the atmosphere does not change its mass), the variation of the global mean surface height does not influence the global mean surface temperature.

\subsection{Greenhouse gas forcing}

The total PE-PR emissivity difference is due to topographic differences (Sect. 4.4; only local effects), due to longwave CRF differences (Sect. 4.3; small global effect), and due to greenhouse gas differences. Subtracting the direct topographic effect, and the longwave cloud radiative effect from the total longwave emissivity effect hence yields the greenhouse gas effect (Fig. 13b, dotted line). According to the 1-D EBM, the global mean PE-PR surface temperature difference due to greenhouse gas differences amounts to $+5.9 \mathrm{~K}$. Since the atmospheric methane and nitrous oxide concentrations in PE are very similar to those in PR (Table 1), the greenhouse gas effect is mostly due to the doubled $p \mathrm{CO}_{2}$ in PE (Table 1), and due to the larger water vapour content (Fig. 13a). The globally averaged, vertically integrated atmospheric water vapour content has almost doubled in PE 
a)

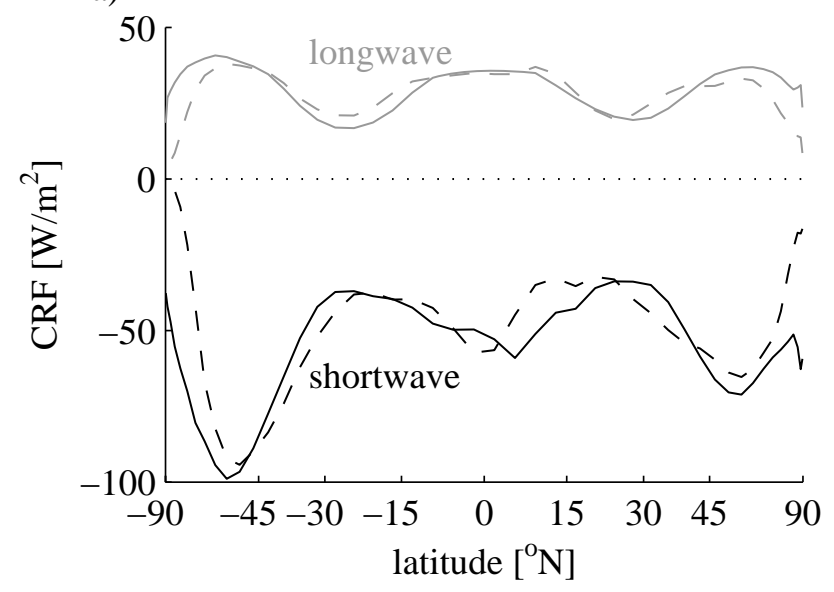

b)

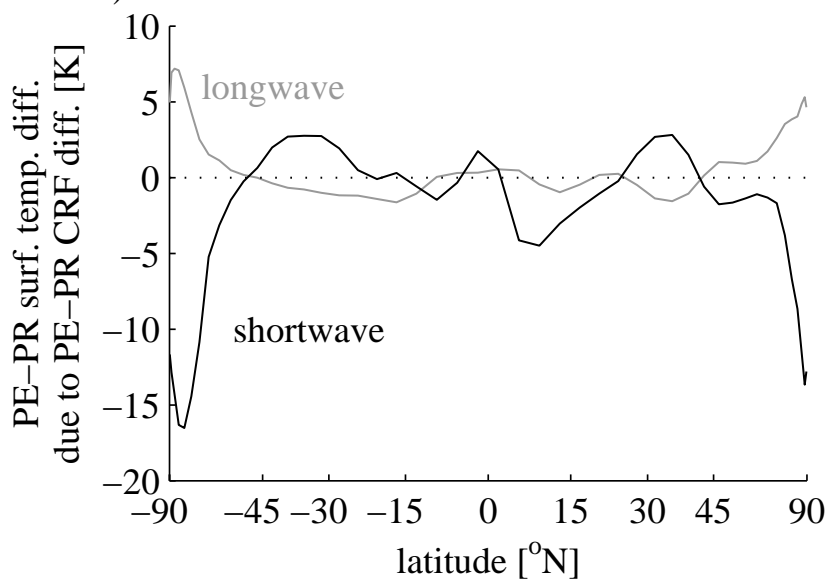

Fig. 12. (a) Zonal mean longwave (grey) and shortwave (black) cloud radiative forcing (CRF) as diagnosed from PE (solid), and PR (dashed); (b) zonal mean PE-PR surface temperature differences due to the PE-PR longwave (grey) and shortwave (black) CRF differences, computed from the 1-D EBM (3) using the clear sky and full sky PE and PR albedos and emissivities. The horizontal scale is linear in the sine of the latitude.

compared to PR (Table 2). While the largest absolute PEPR differences occur in the tropics, the largest relative differences of the water vapour content occur at high latitudes. Unfortunately, we cannot diagnose the radiative forcing of this water vapour increase directly from our GCM setup; however, we can compute the water vapour effect as a residual. The doubled $p \mathrm{CO}_{2}$ yields an additional radiative forcing of about $3.7 \mathrm{Wm}^{-2}$ (Forster et al., 2007). The temperature change due to this additional radiative forcing can be computed from

$\frac{S_{0}}{4}(1-\alpha)+3.7 \mathrm{Wm}^{-2} \equiv \epsilon \sigma \tau_{s, e b m}^{\prime 4}$

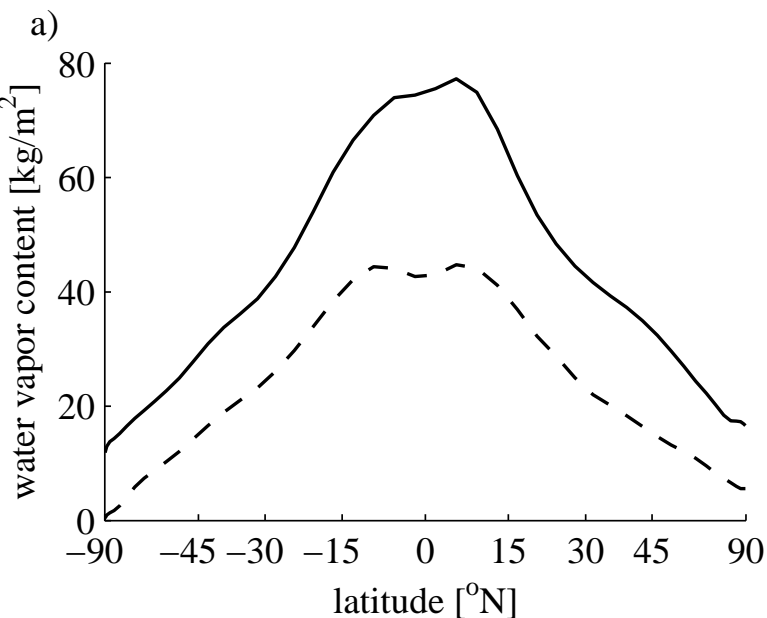

b)

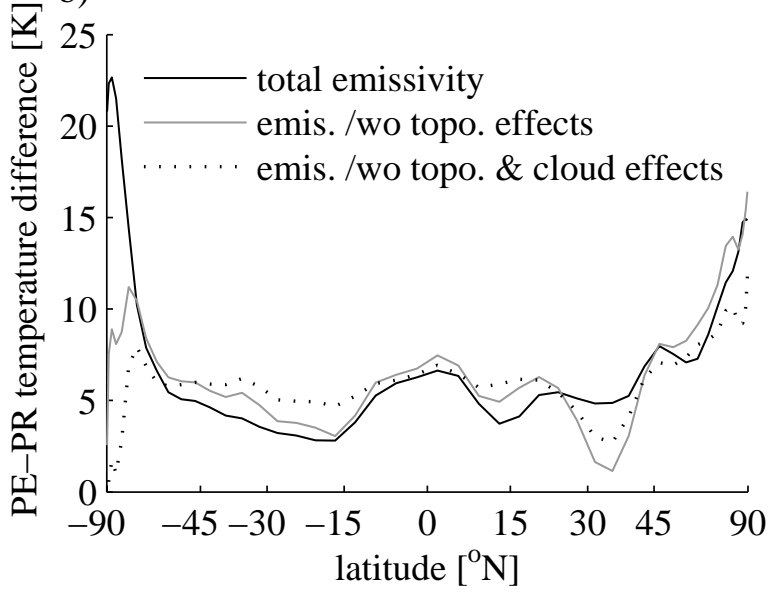

Fig. 13. (a) Zonal mean vertically integrated water vapour in the PE simulation (solid) compared to the pre-industrial simulation (dashed). (b) Zonal mean PE-PR surface temperature difference due to the total PE-PR emissivity difference (solid black line), due to the emissivity difference excluding the direct PE-PR topographic effects (assuming a constant lapse rate, solid grey line), and due to the emissivity difference excluding the topographic differences and the differences of the longwave CRF (dotted line). Hence the dotted line represents mostly the effects of water vapour and $\mathrm{CO}_{2}$. The horizontal scale is linear in the sine of the latitude.

which defines the changed surface temperature $\tau_{s, e b m}^{\prime}$, and results in

$\tau_{s, e b m}^{\prime}-\tau_{s, e b m} \approx 1.1 \mathrm{~K}$.

We ascribe the residual global mean surface temperature difference of $+4.8 \mathrm{~K}$ (total greenhouse gas effect of $+5.9 \mathrm{~K}$ minus $p \mathrm{CO}_{2}$-effect of $+1.1 \mathrm{~K}$ ) to the larger PE atmospheric water vapour content. 
a)

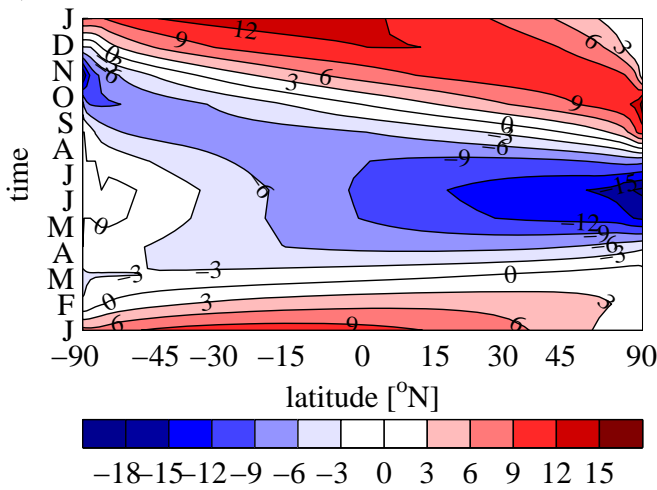

b)

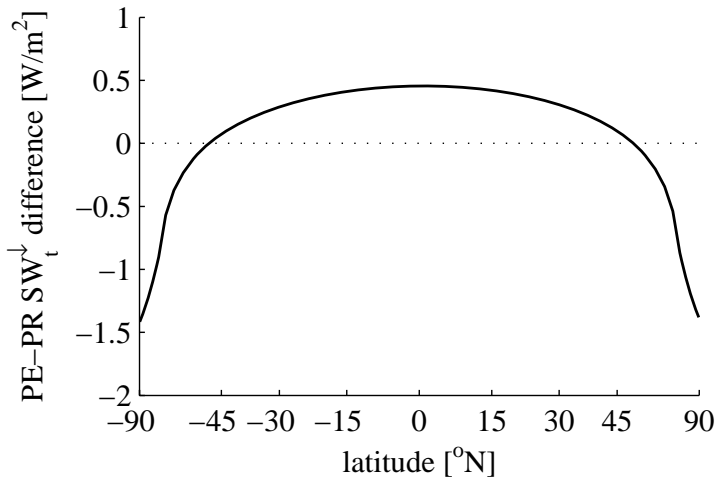

Fig. 14. (a) Seasonal cycle of the difference of the zonal mean incoming shortwave radiation at the top of the atmosphere between PE and $\mathrm{PR}$; red indicates more incoming radiation in PE, blue indicates less radiation in PE. Contour intervals are $3 \mathrm{Wm}^{-2}$. The incoming shortwave radiation in PR is averaged over the last 200 years, i.e. over the years 2800 to 2999 AD. (b) Annual average of the PE-PR incoming shortwave radiation difference. The horizontal scale is linear in the sine of the latitude.

\subsection{Solar and orbital forcing}

The choice of the orbital parameters as described in Sect. 2 leads to the following changes in PE, compared to PR: less incoming shortwave radiation in the Northern Hemisphere in May, June, and July; less incoming radiation in the Arctic spring and autumn; and more radiation mostly during December and January at low and mid latitudes (Fig. 14a). Integrated over the annual cycle, this amounts to about $0.4 \mathrm{Wm}^{-2}$ more incoming shortwave radiation at low and middle latitudes in $\mathrm{PE}$, and about $1 \mathrm{Wm}^{-2}$ less incoming shortwave radiation at high latitudes (Fig. 14b). This redistribution of the incoming shortwave radiation at the top of the atmosphere, from high latitudes to low latitudes, is due to the smaller obliquity in PE compared to PR (Fig. 2). According to the 1-D EBM, the PE-PR obliquity difference leads to a maximum PE-PR temperature difference of about $+0.1 \mathrm{~K}$ around $30^{\circ} \mathrm{N}$, and to a PE-PR temperature difference of about $-0.2 \mathrm{~K}$ and less than $-0.1 \mathrm{~K}$ at the South Pole and the North Pole, respectively (Fig. 10b, orange line). The resulting PE-PR global mean surface temperature difference of less than $+0.03 \mathrm{~K}$ due to the PE-PR obliquity difference is negligible compared to the longwave emissivity and albedo effects.

From the theory of stellar evolution, it is known that the Sun has gradually brightened by more than $30 \%$ since it settled down to steady nuclear burning of hydrogen roughly 4.5 billion years ago (Endal and Sofia, 1981; Peltier, 2003). Due to this brightening, the total solar irradiance $55 \mathrm{Ma}$ ago was up to $0.6 \%$ (about $8 \mathrm{Wm}^{-2}$ ) smaller than at present. According to the 0-D EBM (1), and given the PE albedos and emissivities, the temperature change due to such a reduction of the radiative forcing would amount to less than $-0.5 \mathrm{~K}$.

\section{Discussion and conclusions}

Using the coupled atmosphere-ocean-sea ice general circulation model ECHAM5/MPI-OM, we perform a long, stable climate simulation for the late Paleocene/early Eocene (PE). The simulated PE Earth surface is on average $297 \mathrm{~K}$ warm and ice-free. To our knowledge, we have obtained the first coupled PE simulation with moderate GHG forcing that is warm enough at high latitudes to keep the poles free from sea ice, while reasonably matching the lower latitude SST reconstructions. However, if we take the SST proxy data by Sluijs et al. (2006) at face value, the simulated Arctic surface temperature is still too cold.

A possible shortcoming of this study is the assumption of a globally homogeneous vegetation. Including a more realistic vegetation distribution such as the one reconstructed by Utescher and Mosbrugger (2007) may, at least regionally, affect the climate (Sewall et al., 2000). Also, we did not include lakes in our PE model setup. Including lakes (e.g., the North American Green River lake system) could lead to a further reduction of the seasonality in the continental interiors (Sloan, 1994).

We find that the total atmospheric heat transports in PE and the pre-industrial reference (PR) are very similar, although the latent heat fraction is larger in PE than in PR. The total poleward heat transport by the ocean is smaller in PE compared to PR. We conclude that meridional heat transports do not contribute to the more equable PE climate in our simulation (confirming the results of Huber and Sloan, 2001). A more detailed analysis of the PE ocean circulation will be subject of a future study.

Compared to PR, the simulated PE Earth surface is on average $9.4 \mathrm{~K}$ warmer. While low latitudes in PE compared to $\mathrm{PR}$ are on average about 5 to $8 \mathrm{~K}$ warmer, northern high 
latitudes are warmer by up to $20 \mathrm{~K}$, and southern high latitudes are warmer by up to $40 \mathrm{~K}$. As diagnostic tools to roughly understand this temperature difference, we fit a 0 D EBM, and a 1-D EBM to the PE and PR GCM solutions.

According to the EBMs, one third of the PE-PR surface temperature difference is due to a reduced planetary albedo. The surface albedo in PE compared to PR is reduced mostly due to the lack of glaciers, the lack of sea ice, and reduced snowfall. However, this large high-latitude surface albedo change is partly compensated by a more negative shortwave cloud radiative forcing. In that sense, clouds in our PE model work against the high-latitude amplification of the snow and ice albedo feedback. Nevertheless, the planetary albedo reduction is largest at high latitudes.

Two thirds of the warming are due to a reduction of the effective longwave emissivity. We find that clouds cause a significant reduction of the effective longwave emissivity at high latitudes. This reduction of the emissivity at high latitudes is overcompensated by an increase of the emissivity due to clouds at lower latitudes. This way (via their effect on the longwave emissivity), clouds in PE compared to PR hardly affect the global mean temperature, but they cause a polar warming and a tropical cooling relative to PR.

The reduced orographic height in the PE setup does not directly affect the global mean temperature, but it does have large regional effects. Up to $15 \mathrm{~K}$ of the southern highlatitude PE-PR surface temperature difference are due to the lower Antarctic surface height in PE. The orographic differences contribute to the high-latitude amplification of the clear sky PE-PR emissivity difference. We ascribe the largest fraction of the clear sky emissivity-induced PE-PR surface temperature difference to the water vapour feedback.

As a consequence of the reduced obliquity in our PE setup, a small amount of incoming shortwave radiation at the top of the atmosphere is redistributed from high latitudes to low latitudes. The resulting annual mean reduction of the radiative forcing in PE compared to PR by about $1 \mathrm{Wm}^{-2}$ at high latitudes leads to a negligible increase of the pole-to-equator temperature gradient in the PE simulation compared to PR.

The PE simulation presented here is closer to proxy records than the previously published coupled Eocene simulations by Huber and Sloan (2001) using the National Center for Atmospheric Research (NCAR) Climate System Model (CSM) version 1.4, and by Shellito et al. (2009) using the NCAR Community Climate System Model (CCSM) version 3. We cannot ultimately say why this PE simulation is closer to proxy records than the previous simulations. There are many poorly constrained parameters that may have a large effect on the model solution; greenhouse gases, land surface, vegetation, and soil parameters are obvious examples. We do not know all of these parameters from Huber and Sloan (2001) nor from Shellito et al. (2009), but assuming that the boundary conditions in the previous CSM1.4 and CCSM3 setups were similar to those we use here, CSM1.4 and CCSM3 must have a smaller sensitivity than ECHAM5/MPI-OM with respect to the PE-PR boundary condition differences. This smaller sensitivity with respect to the PE boundary conditions (including the $p \mathrm{CO}_{2}$ doubling) would be in line with the smaller climate sensitivity to a $p \mathrm{CO}_{2}$-doubling alone of the NCAR models compared to ECHAM5/MPI-OM (Kiehl et al., 2006; Randall et al., 2007). One way to analyse the differences between our PE simulation and the previous NCAR Eocene simulations would be to also apply the EBM analysis described here to the NCAR runs. We speculate that especially the water vapour feedback in our simulation is larger than in the NCAR simulations. An explicit investigation of the $p \mathrm{CO}_{2}-$ sensitivity of our PE model solution will be subject of a future study.

Summing up, the warm and equable PE climate as simulated in ECHAM5/MPI-OM is in part due to the smaller surface albedo compared to the pre-industrial reference, but mostly due to a smaller effective longwave emissivity especially at high latitudes as a consequence of topographic effects, cloud effects, and increased $\mathrm{CO}_{2}$ and water vapour concentrations.

Acknowledgements. We thank Helmuth Haak for his help setting up the PE model, and for providing the pre-industrial reference simulation. We thank Karen Bice for advice, and for providing the paleo-topography. We thank three anonymous referees for their productive and helpful comments. We would like to thank Dorian Abbot for discussions, and in particular for his suggestion to extend the 0-D EBM analysis in the meridional direction. The model experiments were carried out on the supercomputing system of the German Climate Computation Centre (DKRZ) Hamburg. This work was completed during a Gary C. Comer Science and Education Foundation Abrupt Climate Change Fellowship.

The service charges for this open access publication have been covered by the Max Planck Society.

Edited by: V. Rath

\section{References}

Abbot, D. S. and Tziperman, E.: Sea ice, high-latitude convection, and equable climates, Geophys. Res. Lett., 35, 1-5, 2008.

Alley, R. B., Marotzke, J., Nordhaus, W., Overpeck, J., Peteet, D., Pielke Jr., R., Pierrehumbert, R., Rhines, P., Stocker, T., Talley, L., and Wallace, J. M.: Abrupt Climate Change: Inevitable Surprises, Natl. Acad. Press, 2002.

Arakawa, A. and Lamb, V. R.: Computational design of the basic dynamical processes of the CLA general circulation model, Meth. Comput. Phys., 17, 173-265, 1977.

Barron, E. J.: Eocene equator-to-pole surface ocean temperatures: a significant climate problem?, Paleoceanography, 2, 729-739, 1987.

Berger, A. L.: Long Term Variations of Daily Insolation and Quaternary Climatic Changes, J. Atmos. Sci., 35, 2362-2367, 1978. 
Bice, K. L. and Marotzke, J.: Numerical evidence against reversed thermohaline circulation in the warm Paleocene/Eocene ocean, J. Geophys. Res., 106, 11529-11542, 2001.

Bice, K. L. and Marotzke, J.: Could changing ocean circulation have destabilized methane hydrate at the Paleocene/Eocene boundary?, Paleoceanography, 17(2), 1018, doi:10.1029/2001PA000678, 2002.

Bretagnon, P. and Francou, G.: Planetary theories in rectangular and spherical variables - VSOP 87 solutions, Astron. Astrophys., 202, 309-315, 1988.

Covey, C. and Barron, E.: The Role of Ocean Heat Transport in Climatic Change, Earth Sci. Rev., 24, 429-445, 1988.

Dickens, G. R., O’Neil, J. R., Rea, D. K., and Owen, R. M.: Dissociation of oceanic methane hydrate as a cause of the carbon isotope excursion at the end of the Paleocene, Paleoceanography, 10, 965-971, 1995.

Endal, A. S. and Sofia, S.: Rotation of Solar Type Stars. I. Evolutionary Models for the Spin-down of the Sun, Astrophys. J., 243, 625-640, 1981.

Estes, R. and Hutchinson, J. H.: Eocene lower vertebrates from Ellesmere Island, Canadian Arctic Archipelago, Palaeogeogr. Palaeoclim. Palaeoecol., 30, 325-347, 1980.

Forster, P., Ramaswamy, V., Artaxo, P., Berntsen, T., Betts, R., Fahey, D., Haywood, J., Lean, J., Lowe, D., Myhre, G., Nganga, J., Prinn, R., Raga, G., Schulz, M., and Dorland, R. V.: Changes in Atmospheric Constituents and in Radiative Forcing, in: Climate Change 2007: The Physical Science Basis. Contribution of Working Group I to the Fourth Assessment Report of the Intergovernmental Panel on Climate Change, edited by: Solomon, S., Qin, D., Manning, M., Chen, Z., Marquis, M., Averyt, K. B., Tignor, M., and Miller, H. L., 129-234, Cambridge University Press, Cambridge, UK and New York, NY, USA, 2007.

Fortuin, J. P. F. and Kelder, H.: An ozone climatology based on ozonesonde and satellite measurements, J. Geophys. Res.Atmos., 103, 31709-31734, 1998.

Fouquart, Y. and Bonnel, B.: Computations of solar heating of the earth's atmosphere: A new parameterization, Beitr. Phys. Atmos., 53, 35-62, 1980.

Gent, P. R., Willebrand, J., McDougall, T., and McWilliams, J. C.: Parameterizing eddy-induced tracer transports in ocean circulation models, J. Phys. Oceanogr., 25, 463-474, 1995.

Greenwood, D. R. and Scott, L. W.: Eocene continental climates and latitudinal temperature gradients, Geology, 23, 1044-1048, 1995.

Griffies, S. M.: The Gent-McWilliams skew flux, J. Phys. Oceanogr., 28, 831-841, 1998.

Hagemann, S.: Report No. 336: An Improved Land Surface Parameter Dataset for Global and Regional Climate Models, Tech. rep., Max Planck Institute for Meteorology, Hamburg, Germany, 2002.

Hagemann, S., Botzet, M., Dümenil, L., and Machenhauer, B.: Report No. 289: Derivation of global GCM boundary conditions from $1 \mathrm{~km}$ land use satellite data, Tech. rep., Max Planck Institute for Meteorology, Hamburg, Germany, 1999.

Hibler, W. D.: A Dynamic Thermodynamic Sea Ice Model, J. Phys. Oceanogr., 9, 815-846, 1979.

Huber, M.: Climate Change: A Hotter Greenhouse?, Science, 321, 353-354, 2008
Huber, M. and Sloan, L. C.: Heat transport, deep waters, and thermal gradients: Coupled simulation of an Eocene Greenhouse Climate, Geophys. Res. Let., 28, 3481-3484, 2001.

Huber, M., Sloan, L. C., and Shellito, C.: Early Paleogene oceans and climate: a fully coupled modelling approach using NCAR's CCSM, in: Causes and Consequences of Globally Warm Climates in the Early Paleogene, edited by: Wing, S. L., Gingerich, P. D., Schmitz, B., and Thomas, E., Geol. Soc. Am. Special Paper Vol. 369, 25-47, 2003.

Jungclaus, J. H., Keenlyside, N., Botzet, M., Haak, H., Luo, J.J., Latif, M., Marotzke, J., Mikolajewicz, U., and Roeckner, E.: Ocean Circulation and Tropical Variability in the Coupled Model ECHAM5/MPI-OM, J. Climate, 19, 3952-3972, 2006.

Kiehl, J. T., Shields, C. A., Hack, J. J., and Collins, W. D.: The Climate Sensitivity of the Community Climate System Model Version 3 (CCSM3), J. Clim., 19, 2584-2596, 2006.

Kump, L. R. and Pollard, D.: Amplification of Cretaceous Warmth by Biological Cloud Feedbacks, Science, 320, p. 195, 2008.

Laskar, J., Robutel, P., Joutel, F., Gastineau, M., Correia, A. C. M., and Levrard, B.: A long term numerical solution for the insolation quantities of the Earth, Astron. Astrophys., 428, 261-285, 2004.

Lin, S. J. and Rood, R. B.: Multidimensional flux-form semiLagrangian transport, Mon. Weather Rev., 124, 2046-2068, 1996.

Lohmann, U. and Roeckner, E.: Design and performance of a new cloud microphysics parameterization developed for the ECHAM4 general circulation model, Clim. Dynam., 12, 557$572,1996$.

Lott, F. and Miller, M. J.: A new subgrid-scale orographic drag parameterization: 1st formulation and testing, Q. J. Roy. Meteor. Soc., 123, 101-127, 1997.

Luo, J.-J., Massen, S., Roeckner, E., Madec, G., and Yamagata, T.: Reducing climatology bias in an ocean-atmosphere CGCM with improved coupling physics, J. Climate, 18, 2344-2360, 2005.

Markwick, P. J.: 'Equability,' continentality, and Tertiary 'climate': The crocodilian perspective, Geology, 22, 613-616, 1994.

Markwick, P. J.: Fossil crocodilians as indicators of Late Cretaceous and Cenozoic climates: implications for using palaeontological data in reconstructing palaeoclimate, Palaeogeogr. Palaeoclim. Palaeoecol., 137, 205-271, 1998.

Marsland, S. J., Haak, H., Jungclaus, J. H., Latif, M., and Röske, F.: The Max-Planck-Institute global ocean/sea ice model with orthogonal curvilinear coordinates, Ocean Model., 5, 91-127, 2003.

Mlawer, E. J., Taubman, S. J., Brown, P. D., Iacono, M. J., and Clough, S. A.: Radiative transfer for inhomogeneous atmospheres: RRTM, a validated k-correlated model for the longwave, J. Geophys. Res., 102, 16663-16682, 1997.

Pacanowski, R. C. and Philander, S. G. H.: Parameterization of vertical mixing in numerical models of tropical oceans, J. Phys. Oceanogr., 11, 1443-1451, 1981.

Pearson, P. N. and Palmer, M. R.: Atmospheric carbon dioxide concentrations over the past 60 million years, Nature, 406, 695-699, 2000.

Pearson, P. N., van Dongen, B. E., Nicholas, C. J., Pancost, R. D., Schouten, S., Singano, J. M., and Wade, B. S.: Stable warm tropical climate through the Eocene Epoch, Geology, 35, 211-214, 2007. 
Peltier, W. R.: Earth System History, in: Encyclopedia of Global Environmental Change, Volume One, The Earth system: physical and chemical dimensions of global environmental change, John Wiley \& Sons, Ltd, 31-60, 2003.

Randall, D., Wood, R., Bony, S., Colman, R., Fichefet, T., Fyfe, J., Kattsov, V., Pitman, A., Shukla, J., Srinivasan, J., Stouffer, R., Sumi, A., and Taylor, K.: Climate Models and Their Evaluation, in: Climate Change 2007: The Physical Science Basis. Contribution of Working Group I to the Fourth Assessment Report of the Intergovernmental Panel on Climate Change [Solomon, S., D. Qin, M. Manning, Z. Chen, M. Marquis, K.B. Averyt, M. Tignor and H.L. Miller (eds.)], pp. 589-662, Cambridge University Press, Cambridge, UK and New York, NY, USA, 2007.

Roeckner, E., Bäuml, G., Bonaventura, L., Brokopf, R., Esch, M., Giorgetta, M., Hagemann, S., Kirchner, I., Kornblueh, L., Manzini, E., Rhodin, A., Schlese, U., Schulzweida, U., and Tompkins, A.: The atmospheric general circulation model ECHAM5, Tech. rep., Max Planck Institute for Meteorology, Hamburg, Germany, available online at: http://www.mpimet. mpg.de, 2003.

Royer, D. L., Wing, S. L., Beerling, D. J., Jolley, D. W., Koch, P. L., Hickey, L. J., and Berner, R. A.: Paleobotanical Evidence for Near Present-Day Levels of Atmospheric $\mathrm{CO}_{2}$ During Part of the Tertiary, Science, 292, 2310-2313, 2001.

Semtner, A. J.: A Model for the Thermodynamic Growth of Sea Ice in Numerical Investigations of Climate, J. Phys. Oceanogr., 379-389, 1976.

Sewall, J. O., Sloan, L. C., Huber, M., and Wing, S.: Climate sensitivity to changes in land surface characteristics, Global Planet. Change, 26, 445-465, 2000.

Sexton, A. J., Wilson, P. A., and Pearson, P. N.: Microstructural and geochemical perspectives on planktic foraminiferal preservation: 'Glassy' versus 'Frosty', Geochemistry Geophysics Geosystems, 7, 2006.

Shackleton, N. and Boersma, A.: The climate of the Eocene ocean, J. Geol. Soc. London, 138, 153-157, 1981.

Shellito, C. J., Sloan, L. C., and Huber, M.: Climate model sensitivity to atmospheric $\mathrm{CO}_{2}$ levels in the Early-Middle Paleogene, Palaeogeogr. Palaeoclim. Palaeoecol., 193, 113-123, 2003.

Shellito, C. J., Lamarque, J.-F., and Sloan, L. C.: Early Eocene Arctic climate sensitivity to $p \mathrm{CO}_{2}$ and basin geography, Geophys. Res. Lett., 36, 1-5, 2009.

Sloan, L. C.: Equable climates during the early Eocene: significance of regional paleogeography for North American climate, Geology, 22, 881-884, 1994.

Sloan, L. C. and Barron, E. J.: 'Equable' climates during the Earth history?, Geology, 18, 489-492, 1990.
Sloan, L. C. and Pollard, D.: Polar stratospheric clouds: A high latitude warming mechanism in an ancient greenhouse world, Geophys. Res. Lett., 25, 3517-3520, 1998.

Sloan, L. C., Walker, J. C. G., and Moore Jr., T. C.: Possible role of oceanic heat transport in early Eocene climate, Paleoceanography, 10, 347-356, 1995.

Sluijs, A., Schouten, S., Pagani, M., Woltering, M., Brinkhuis, H., Damste, J. S. S., Dickens, G. R., Huber, M., Reichart, G.-J., Stein, R., Matthiessen, J., Lourens, L. J., Pedentchouk, N., Backman, J., Moran, K., and the Expedition 302 Scientists: Subtropical Arctic Ocean temperatures during the Palaeocene/Eocene thermal maximum, Nature, 441, 610-613, 2006.

Smith, R. S., Dubois, C., and Marotzke, J.: Global Climate and Ocean Circulation on an Aquaplanet Ocean Atmosphere General Circulation Model, J. Climate, 19, 4719-4737, 2006.

Tanré, D., Geleyn, J.-F., and Slingo, J. M.: First results of the introduction of an advanced aerosol-radiation interaction in the ECMWF low resolution global model, in: Aerosols and their climatic effects, 133-177, 1984.

Thomas, D. J., Zachos, J. C., Bralower, T. J., Thomas, E., and Bohaty, S.: Warming the fuel for the fire; evidence for the thermal dissociation of methane hydrate during the Paleocene-Eocene thermal maximum, Geology, 30, 1067-1070, 2002.

Tripati, A. and Elderfield, H.: Abrupt hydrographic changes in the equatorial Pacific and subtropical Atlantic from foraminiferal $\mathrm{Mg} / \mathrm{Ca}$ indicate greenhouse origin for the thermal maximum at the Paleocene-Eocene Boundary, Geochem. Geophys. Geosys. 5, 2004.

Utescher, T. and Mosbrugger, V.: Eocene vegetation patterns reconstructed from plant diversity - A global perspective, Palaeogeogr. Palaeoclim. Palaeoecol., 247, 243-271, 2007.

Zachos, J. C., Pagani, M., Sloan, L., Thomas, E., and Billups, K.: Trends, rhythms, and aberrations in global climate $65 \mathrm{Ma}$ to Present, Science, 292, 686-693, 2001.

Zachos, J. C., Wara, M. W., Bohaty, S., Delaney, M. L., Petrizzo, M. R., Brill, A., Bralower, T. J., and Premoli-Silva, I.: A Transient Rise in Tropical Sea Surface Temperature During the Paleocene-Eocene Thermal Maximum, Science, 302, 15511554, 2003.

Zachos, J. C., Schouten, S., Bohaty, S., Quattlebaum, T., Sluijs, A., Brinkhuis, H., Gibbs, S. J., and Bralower, T. J.: Extreme warming of mid-latitude coastal ocean during the Paleocene-Eocene Thermal Maximum: Inferences from $\mathrm{TEX}_{86}$ and isotope data, Geology, 34, 737-740, 2006. 